UCRL-52971

Distribution Category UC-21

\title{
DISCLAIMER
}

This report was prepared as an accoint of work sponsored by an agency of the United States Govemment. Neither the United States Government nor any agency thereof, nor any of their employees, makes any warranty, express or implied, or asoumes any legal liability or responsjbility for the sccuracy, completeress, or usefulness of any information, apparatus, product, or process discloeed, or represents that its use would not inftinge privately owned rights. Refereace herein to any specilic commercial product, process, or service by trade name, trademark, manufacturer, or otherwise does not necessarily constitute or imply its endorsement, recommendation, or favoring by the United States Government or any agency thereof. The views and opinions of authors expressed herein do not necessarily state or reflect those of the United Stales Govemment or any agency thereof.

\section{High energy laser optics manufacturing: A preliminary study}

\author{
E. Douglas Baird
}

Manuscript date: July 1980

\section{LAWRENCE LIVERMORE NATIONAL LABORATORY University of California - Livermore, California - 94550}

UCRL- -52971

DE84 004740 


\section{CONTENTS}

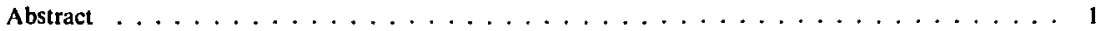

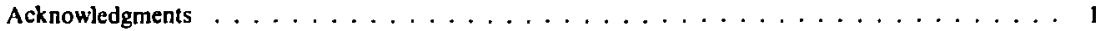

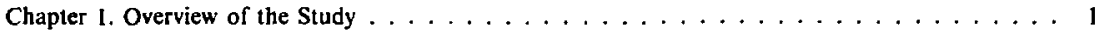

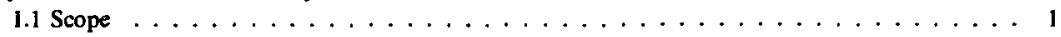

1.2 Study Approach $\ldots \ldots \ldots \ldots \ldots \ldots \ldots \ldots \ldots \ldots$

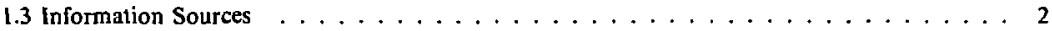

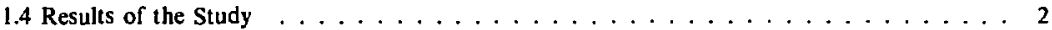

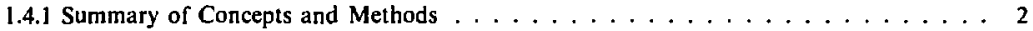

1.4.1.1 Metrological Operations . . . . . . . . . . . . . . . . . 2

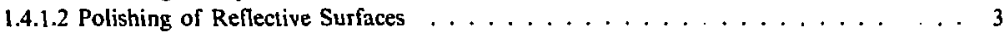

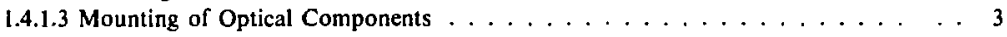

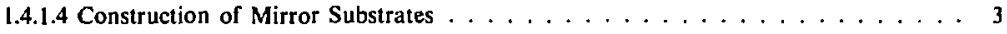

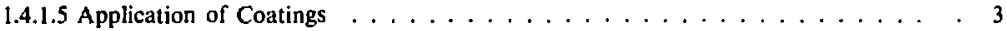

1.4.2 Major Conclusions of the Study . . . . . . . . . . . . . . . . . 3

1.4.2.1 Conclusions Specific to the Alpha Laser Program . . . . . . . . . . . 3

1.4.2.2 General Conclusions . . . . . . . . . . . . . . . . . 4

1.4 .3 Major Recommendations of the Study . . . . . . . . . . . . . . . 4

1.5 Optics Model Used in Development of Metrology $\ldots \ldots \ldots \ldots \ldots \ldots \ldots \ldots \ldots$

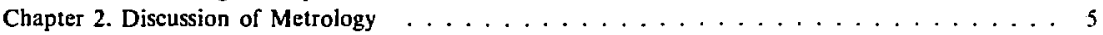

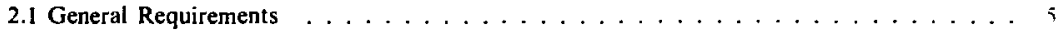

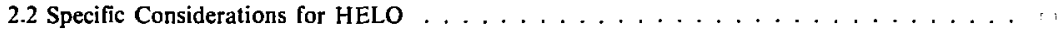

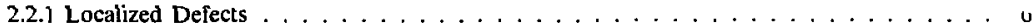

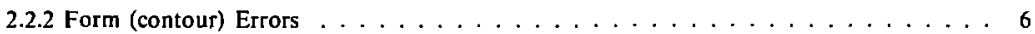

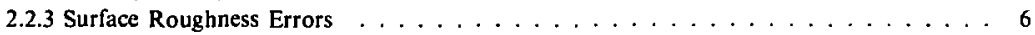

2.3 Specific Metrology Requirements for HELO . . . . . . . . . . . . . . 6

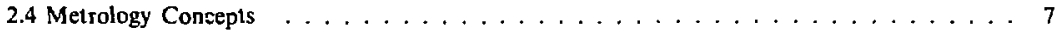

2.4.1 Concepts to Identify Localized Defects $\ldots \ldots \ldots \ldots \ldots$

2.4.1.1 Scanning Scatter Measurement . . . . . . . . . . . . . . . . 7

2.4.1.2 Scanning Interference Microscopy . . . . . . . . . . . . . . 7

2.4.2 Concepts to Identify Form (contour) Errors . . . . . . . . . . . . . . . . 8

2.4.2.1 Mechanical Methods . . . . . . . . . . . . . . . . . . 8

2.4.2.2 Optical Methods . . . . . . . . . . . . . . . . 10

2.4.2.2.1 Full Aperture Phase Measuring $\ldots \ldots \ldots \ldots \ldots \ldots \ldots$

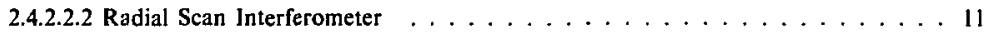

2.4.3 Concepts to Identify Surface Roughness Errors . . . . . . . . . . . . . . 16

2.4.3.1 General . . . . . . . . . . . . . . . . . . . . . . . . . . . . . . . . . . . .

2.4.3.2 Scanning Scatter Measurement . . . . . . . . . . . . . . . 16

2.4.3.3 Heterodyne Surface Profiling . . . . . . . . . . . . . . 17

2.4.3.4 Stylus Profilometry . . . . . . . . . . . . . . . . 17

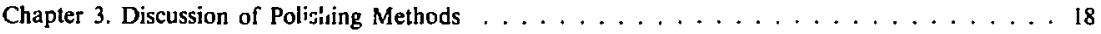

3.1 General Discussion . . . . . . . . . . . . . . . . . . 18

3.2 Additional Considerations for Polishing $\ldots \ldots \ldots \ldots \ldots \ldots$

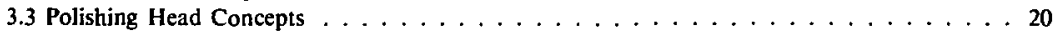

3.3.1 Fluid Bearing Belt Lap . . . . . . . . . . . . . . . . . . . 20

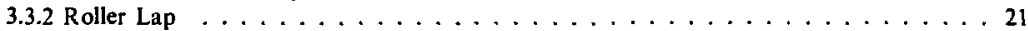

3.4 Polar Polishing Machine . . . . . . . . . . . . . . . . . . . 22

3.5 Other Concepts for Removal of Material $\ldots \ldots \ldots \ldots$ 
Chapter 4. Discussion of Mounting, Substrates, and Coatings . . . . . . . . . . . . . 24

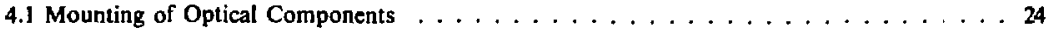

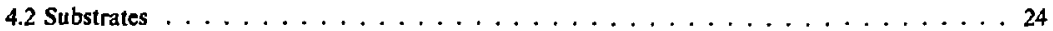

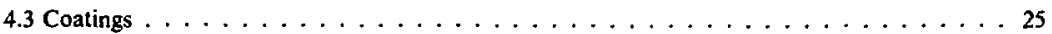

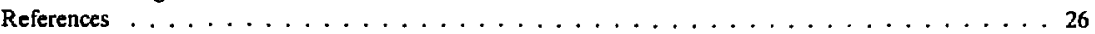

Appendix A. Site Visits and Personnel Contacted for the Preliminary Study . . . . . . . 28 


\section{High energy laser \\ optics manufacturing: \\ A preliminary study}

\section{ABSTRACT}

This report presents concepts and methods, major conclusions, and major recommendations concerning the fabrication of high energy laser optics (HELO) that are to be machined by the Large Optics Diamond Turning Machine (LODTM) at the Lawrence Livermore National Laboratory (LLNL). Detailed discussions of concepts and methods proposed for metrological operations, polishing of reflective surfaces, mounting of optical components, construction of mirror substrates, and applications of coatings are included.

\section{ACKNOWLEDGMENTS}

The author would like to acknowledge the valuable contributions of the LLNL Mechanical Engineering Department, Materials Fabrication Division, Optics, Machine Tool Development, and
Metrology Groups for the preparation of the sections of the report on metrology and polishing methods.

\section{CHAPTER 1. OVERVIEW OF THE STUDY}

\subsection{SCOPE}

This report summarizes the results of a preliminary study to determine what is needed to fabricate high energy laser optics (HELO) that are to be machined by the Large Optics Diamond Turning Machine (LODTM) at Lawrence Livermore National Laboratory (LLNL). The study is a natural extension of the LODTM project already underway at LLNL in support of Defense Advanced Research Projects Agency (DARPA) sponsored laser programs.

The HELO of interest here are primarily resonator reflective optics with metal substrates and may be up to $1.5 \mathrm{~m}$ in diameler. They will be ured in high power chemical lasers havirg operating wavelengths of from 2 to $4 \mu \mathrm{m}$. The resonator optics must be actively cooled, and the reflective surfaces often have complex shapes, including toroids. These HELO require the ultimate in precision for all manufacturing operations including substrate construction, machining, polishing, and application of multi layer dielectric thin films.
Chapter 1 describes the appreach used in the study, cites the information sources used, and summarizes major thrusts, conclusions, and recommendations of the study. The chapter concludes with a description of the model used for development of meirology and polishing concepts discussed in the remaining chapters. Those chapters focus on specifics related to metrology, polishing methods, mountings, substrates, and coatings.

\subsection{STUDY APPROACH}

Because of time constraints, attention was focused on specific requirements of a few existing and planned laser programs undertaken by DARPA and the Air Force Weapons Laboratory (AFWL) at Kirtland Air Force Base, Albuquerque, NM. Needs within these programs for high energy laser optics are common to a broad range of programs now funded by the Army, Navy, Air Force, and DARPA.

Early in the study, it became evident that the following five manufacturing operations should be 
clearly defined and analyzed because of their importance to the overall manufacturing process:

1. Metrological operations (mechanical and optical).

2. Polishing of the reflective surfaces.

3. Mounting of optical components for fabrication, testing, and for use in laser systems.

4. Construction of mirror substrates.

5. Application of coatings.

Related technologies of diamond turning, surface microtopography, surface damage from lasers, and resonator design were evaluated and applicable parameters included in requirements for the above manufacturing operations.

\subsection{INFORMATION SOURCES}

Information and evaluations were obtained through:

1. A literature search.

2. Private communications with technical personnel at LLNL, University of Arizona Optical Sciences Center, University of Dayton Research Institute (UDRI), AFWL, Development Optical Facilities at AFWL, Perkin Elmer Corporation, Honeywell Electro Optics Cintur, and Naval Weapons Center (Michelson Laboratory).

3. Attendance at a meeting of the High Energy Laser Review Group (HELRG) at AFWL, March 19-20, 1980.

Site visits were made to all of the organizations listed above. A list of sites visited and personnel contacted is given in Appendix A. Some information relative to the DARPA Alpha Laser program was contributed by R. W. Dyer of W. J. Schaffer Associates, a consulting firm retained by DARPA.

\subsection{RESUITS OF THE STUDY}

Definition and analysis were made of each of the five manufacturing operations listed in Sec. 1.2. The next three subsections, respectively, contain a list of concepts and methods that were considered for each of the five operations, a summary of the major conclusions of the study, and a summary of the major recommendations resulting from the study.

\subsubsection{Summary of Concepts and Methods}

1.4.1.1 Metrological Operations. Metrology requirements for HELO were divided into three important areas:

1. Detection and measurement of localized surface defects in the form of pits, scratches, "bumps," and inclusions.

2. Measurement of the form (contour) errors.

3. Measurement of surface roughness errors. Approximate ranges of magnitudes were developed for lateral size, surface normal error, and lateral spacing ranges for each of the three metrology categories (see Table 3, Sec. 2.3), to aid in selecting appropriate metrological concepts.

The concepts analyzed and determined to be suitable for use in meeting the above metrology requirements are summarized in Table 1.

TABLE 1. Summary of concepts determined to be useful in meeting metrology requirements, glong with location of sections where they are discussed in detail.

Purpose of concept Concept Discussed in

1. To detect and measure locnlized effects

2. To detect and measure form (contour) errors
3. To detect and measure surface rowghess errors
1. Scanning scatter measurements

2. Scanniag interference microscopy

1a. Roundness measuring instrumentation using duplicate LODTM spindle (azimuthal errors only)

lb. Use of LODTM to measure radial etrors

2. Full aperture phosse measuring interferometer

3. Radial scan interferometer

1. Scanning scatter mensurement

2. Heterodyne surface profiler

3. Stylus profilometry
Sec. 2.4.1.1

Sec. 2.4 .1 .2

Sec. 2.4.2.1

Sec. 2.4.2.2.1

Sec. 2.4.2.22

Sec. 2.4 .3 .2

Sec. 2.4 .3 .3

Sec. 2.4.3.4 
1.4.1.2 Polishing of Reflective Surfaces. General and specific requirements related to polished diamond-turned optics are identified in Sec. 3.1 and 3.2. Concepts for two promising polishing heads are presented in Sec. 3.3. A seven-axis computer numerical control (CNC) polar polishing machine that could be developed to position and move the polishing heads is described in Sec. 3.4.

1.4.1.3 Mounting of Optical Components. Very little information could be obtained in this preliminary study relative to the Alpha Laser substrate design and construction. However, a plan was developed for a two phase study of how concepts of mounting used in connection with astronomical telescopes might be applied to the design of mountings for HELO. The first phase will be analytical with emphasis on finite element modeling. The second phase will involve detail modeling of actual component designs, experimental testing, and construction and testing of full-scale mounts or fjxiures. See Sec. 4.I.

1.4.1.4 Construction of Mirror Substrates. Severe substrate problems have been experienced recently in many applications with respect to corrosion in the internal cooling passages, and cracking, warping, and long term creep in mirror faceplates. ${ }^{I}$ Developmental methods to investigate the potential use of new materials, new designs, and methods of fabrication have been started. 2

No delinitive information on Alpha Laser substrate design and construction could be found during the course of this preliminary study. See Sec. 4.2.

1.4.1.5 Application of Castings. Functional requirements, methods of deposition, metrology concepts, and special equipment needed for multilayer dielectric coating of large reflective optics have been described in a comprehensive study recently completed by H. E. Bennett of Naval Weapons Center, China Lake, CA. ${ }^{3}$

Bennett's study shows that there are a number of important trade-offs between thermal (and structural) distortions, finishing form (contour) errors, and coating deposition uniformity errors. These trade-offs must be carefully evaluated in the development of a practical overall plan for manufacturing HELO. See Sec. 4.3.

\subsubsection{Major Conclusions of the Study \\ 1.4.2.1 Conclusions Specific to the Alpha Laser Program.}

1. The axicon reflector is the most difficult and challenging optical component of the Alpha Laser system to manufacture.

2. Beyond development of the LODTM, the most important step in the manufacture of HELO is the development of adequate metrological methods to measure localized defects, form (contour) errors, and surface roughness errors.

3. The metrology requirements are rather severe, covering a range of surface normal errors from $0.015 \mu \mathrm{m}(0.6 \mu \mathrm{in}$.) to $0.095 \mu \mathrm{m}(3.8 \mu \mathrm{in}$.), and lateral spacing from about $1 \mu \mathrm{m}(40 \mu \mathrm{in}$.) to $0.75 \mathrm{~m}$ (30 in.).

4. None of the measurement requirements are beyond the present state-of-the-art for small size optics (i.e., $5 \mathrm{~cm}$, or 2 in. in diameter); however, some rather sophisticated scanning type instruments will have to be developed for measuring localized defects and form (contour) errors for $1.5 \mathrm{~m}$ diameter optics.

5. Polishing or "smoothing" of the reflective surfaces, as machined by the LODTM, will probably be required if scattering and absorption levels must be 0.1 percent or less (Sec. 2.2.3) and/or reflectivities of azimuthal and radial polarizations must be within 2 percent or less of each other (Sec. 3.2).

6. If polishing of the reflective surfaces is required, some new polishing head concepts and a CNC polishing machine will nost likely be needed to maintain the form (contour) accuracy of surfaces machined by the LODTM (Secs. 3.1, 3.3, 3.4).

7. Substrates will most likely experience significant changes in the next few years with respect to materials, type of construction, and manufacturing methods (Sec. 4.2).

8. Thin film coating requirements for large aperture ( 0.5 to $4 \mathrm{~m}$ in diameter) mirrors have been well defined in several recent U.S. Government funded studies and are applicable to the Alpha Laser program (Sec. 4.3).

9. The total error for surface form (contour) is made up of three important parts:

a. errors resulting from system/operating effects.

b. errors generated in the finishing operations.

c. errors generated in the deposition of thin film coatings. See Sec. 4.3.

10. Proportioning of the total allowable error for surface form (contour) into the above three parts can have a significant effect on the overa!l cost of mirror fabrication. 


\subsubsection{General Conclusions.}

1. Optics manufacturing has become recognized as the critical path technology whose development is most essential for building present and future high energy laser (HEL) systems. ${ }^{4}$

2. There is a recognized national need for a complete development and manufacturing capability for HELO.

3. There is no clearly identifiable organization in the U.S. at this time with the capability for development and complete fabrication of HELO (e.g., fabrication of substrates, finishing and coating of reflective surfaces).

4. An in-depth plan is needed for development and manufacture of HELO that will satisfy near-term and future requirements of Department of Defense (DOD) programs.

\subsubsection{Major Recommendations of the Study}

1. A detailed plan should be constructed for the design and building of a metrology system for Alpha Laser optics. The plan should include equipment, instruments, facilities, and personnel needs.

2. Experimental evaluation of the optical properties (including laser damage) of metal surfaces as they are projected to be finished on the LODTM, and later polished and coated, should be started now to determine if surface polishing (smoothing) is necessary and/or desirable.

3. Experimental development of at least two polishing head concepts, as outlined in this report, should be started in paraliel with the work recommended in 2 above.

4. Design of the CNC polishing machine should be started only when the results of the work recommended in 2 and 3 above show sufficient need.

5. Design of mountings or fixtures for HELO as outlined in this report (Sec. 4.1) should be started early in the laser system development, to avoid potential interface conflicts and schedule delays.

6. Development efforts in substrates, and in the mounting, finishing, and coating of HELO should be carefully integrated and managed by a central organization to assure not only meeting of Alpha Laser program goals but also maximum return on the development investment.

\subsection{OPTICS MODEL USED IN DEVELOPMENT OF METROLOGY AND POLISHING CONCEPTS}

The waxicon reflector shown in Fig. 1, with parameters listed in Table 2, was used as a model for the development of metrology and polishing concepts. This waxicon is a composite specification formulated by R. W. Dyer, of W. J. Schaffer Associates, Inc., using inputs obtained from three Alpha Laser program contractors (Bell Aerospace, Rocketdyne, and TRW).

The Alpha Laser uses a half-symmetric unstable resonator with internal axicon (HSURIA). The optical components of this type of resonator have surface shapes that are flat, spherical, or aspherical. The most dificult and challenging component to manufacture is the axicon (or reflaxicon) having aspherical surfaces of revolution that must be formed and finished to very close tolerances (i.c., microinches).

The LODTM will have the capability of machining all of the above surface shapes, including axicons. The roughness of the as-machined surfaces is projected to be $42 A \mathrm{rms}$ (see Ref. 5, Table 3.1).

TABLE 2. Preliminary waxicon parameters.

\begin{tabular}{ll}
\hline Outside diameter & $134 \mathrm{~cm}(52.8 \mathrm{in})$. \\
Optical clear aperture & $93 \mathrm{~cm}(36.6 \mathrm{in})$. \\
Thickness $^{2}$ & $34 \mathrm{~cm}(13.4 \mathrm{in})$. \\
Tool stroke & $15 \mathrm{~cm}(5.9 \mathrm{in.})$ \\
Average surface slope $_{\text {Slope variation }}$ & $\pi / 4 \mathrm{rad}\left(45^{\circ}\right)$ \\
Max local curvature & $\pm 175 \mathrm{mrad}^{\mathrm{c}}\left( \pm 10^{\circ}\right)$ \\
Weight & $0.17 \mathrm{~cm}^{-1}\left(0.42 \mathrm{in}^{-1}\right)$ \\
Unbalanced weight & $400 \mathrm{~kg}^{-1}(880 \mathrm{lb})$ \\
l'ressurization & Negligible
\end{tabular}

\footnotetext{
The contractors conceive their optics as mounting directly to the face plate (or on very short stand-offs) so that the pisce part thickness is the total thickness on the spindle.

bThe surfaces are concave. This can result in a very "shurp" point at the tip-totel cone angles as low as $60^{\circ}\left(30^{\circ}\right.$ from axis).

CThe largest curratures occur on the outer axicon.

dPresent concepts use lightweight optics. The final tements may be of conventional laboratory design and weigh as much as $\$ 00 \mathrm{~kg}$.

'The contractors don't want to eliminate the possible use of dynamic pressurization. Subsequent analysis may show it is reed ad.
} 


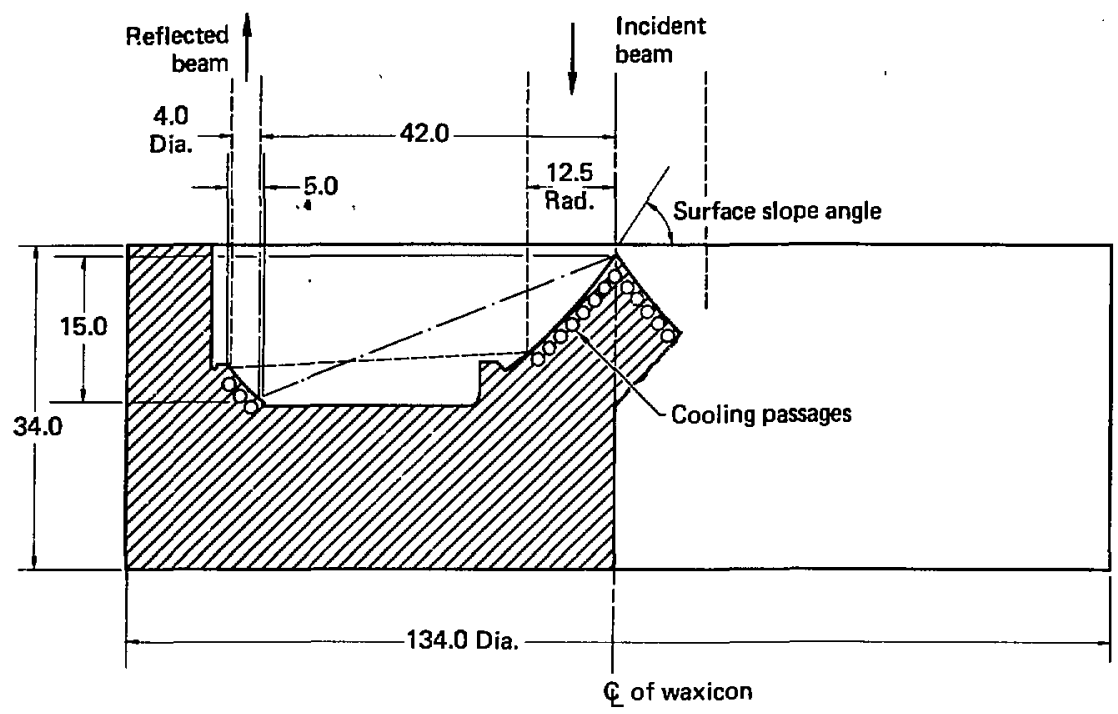

Note: All dimensions are in $\mathrm{cm}$.

FIG. 1. Waxicon design for Alpha Laser program showing inner and outer optical surfaces.

These surfaces are expected to have a highly correlated (grooved) structure with some lowspatial-irrequency slope errors that are typical of very smooth surfaces produced by machining with a single point diamond tool (see Refs. 6, 7). The following sections describe some projected methods for metrological and polishing operations that can be developed to produce an uncorrelated, smooth (i.e., 10 to $20 A$ rms) surface starting with an accurately machined diamond-turned (D-T) substrate.

\section{CHAPTER 2. DISCUSSION OF METROLOGY}

\subsection{GENERAI, REQUIREMENTS}

Application of ade guate metrology has long been recognized as the key to successfi' manufac. turing processes. Considering the level of difficulty of fabricating the optics described abcve, we at LLNL have concluded that for every step in the manufacturing process, from machining to dielectric coating, the metrological methods employed must:

1. Be sufficiently accurate and repeatable to meet the allotted budgets for errors within that step.

2. Provide data that can be directly related to cause and effect mechanisms of the particular process step.
3. Produce data in a form that can be quantitatively and conveniently related to the previous and the following manufacturing/metrological steps.

4. Produce final data that will define performance parameters of the individual part. or combination of parts, and which is understandable and useful to the user (e.g., data related to wavefront distortion, reflectivity, absorption, and scattering).

In addition, it would be desirable to use more than one independent method of measurement for some of the more important parameters, such as form (cuntour) and surface roughnesses. 


\subsection{SPECIFIC CONSIBERATIONS FOR HEI.O}

The following subsections identify observations and limitations that are important in the setting of metrological requirements for HELO.

\subsubsection{Localized Defects}

Localized surface defects in the form of pits, scratches, "bumps," and inclusions can drastically lower the threshold at which laser damage occurs, ${ }^{8}$ and can cause parasitic scattering. These macroscopic defects may have alriost any lateral size and may be important, down to about $0.1 \mathrm{~m}, \mathrm{n}(0.004$ in.), for continuous wave (cw) lasers operating at near infrared (IR) wavelengths. ${ }^{3}$

\subsubsection{Form (contour) Errors}

Surface form (contour) errors produce wavefront (phase) distortions internal and external to the resonator. The net effect is a reduction in the beam intensity at the focus of the beam transport system. Reductions in intensity depend upon the magnitude and shapes of the surface contour errors and can be substantial for small errors. We chose the lower cutoff spatial wavelength for this type of error to be $100 \mu \mathrm{m}$ (0.004 in.), which is consistent with Donaldson's criteria for D-T machining. ${ }^{5}$ Surface normal contour errors as low as $27 \mathrm{~nm}(1.07 \mu \mathrm{in}$.) peak-to-valley (P-V) may be the upper allowable limit for some of the more critical optical components. ${ }^{5}$

\subsubsection{Surface Roughness Errors}

Roughness errors, a parl of surface microtopography, can significantly contribute to scattering, absorption, and surface damage from lasers. According to H. E. Bennet ${ }^{3}$ " "light scattering from optically polished surfaces in the visible and near infrared region is determined primarily by surface microroughness, ir regularities with rms heights about the mean surface level of $100 A$ or less, and lateral dimensions of from a few thousand angstroms to 10 or $20 \mu \mathrm{m}$."

In the same study, ${ }^{3} \mathrm{H}$. E. Bennett points out that although the influence of surface microroughness on absorption is much more subtle and less well understood, "the data that exists suggests that infrared absorption of coatings deposited on substrates having high micro roughness value is of- ten significantly higher than that on surfaces having a low microroughness value."

Decker" have also shown that "the properties influencing laser damage include surface microtopography, as well as bulk physical and chemical structure."

A polished metal surface has a more or less randont residual structure in contrast to a D-T metal surface, which has a periudic and therefore highly correlated structure. In fact, under some combinations of feed rate (with resultant groove periodicity), angle of incidence, and wavelength, a significant amount of incident radiation diffracted into the first octer can be intercepted by the side of the groove and therefore scattered or absorbed. ${ }^{\text {In }}$

Diamond-turned surfaces also may have some peculiar areas of ncmperiodic, nonisotropic. grooved, low amplitude roughness. Stover postulates that these rough areas may be caused by the chip scraping on the part.

The metrology used to measure surface microroughness shouid have the capability of resolving $P \cdot V$ errors on surfaces machined by LODTM, and on polished surfaces with roughness as low as about $10 A \mathrm{rms}(1 \mathrm{~nm}$ or $0.04 \mu \mathrm{in}$. rms). The upper limit of expected P-V errors would then be about $0.015 \mu \mathrm{m}(0.6 \mu \mathrm{in}$.) for LODTM machined surfaces (see Ref. 5, Table 3.1), and the lower limit about $0.0035 \mu \mathrm{m}(0.14 \mu \mathrm{in}$.) for a smooth (i.e., $10 \AA$ rms) polished surface.

The upper limit of lateral spatial wavelength for roughness errors will be the same as the lower cut-off wavelength for errors of form, namely 100 $\mu \mathrm{m}(0.004 \mathrm{in}$ ). The lower cut-off spatial wavelength for roughness errors of interest is about $1 \mu \mathrm{m}$ ( 40 $\mu \mathrm{in}$.$) , for an operating spectral wavelength of 2.8$ $\mu \mathrm{m}$.

\subsection{SPECIFIC METROLOGY REQUIREMENTS FOR HELO}

Table 3 summarizes specific metrology requirements for HELO with an operating wavelength of $2.8 \mu \mathrm{m}$. So far as they have been determined, limitations on the sizes of the three types of errors described in Sec. 2.2 are shown. The appearance of $U$ in the table indicates that the limit on the allowable defect or error size is presently undetermined. 
TABLE 3. Summary of HELU sperilfe metrology requirements for an operating wavelength of $2.8 \mu \mathrm{m}$.

\begin{tabular}{|c|c|c|c|}
\hline Type el error & $\begin{array}{l}\text { Lateral size } \\
\text { range }\end{array}$ & $\begin{array}{l}\text { Surface mormal } \\
\text { peak-to-ralley } \\
\text { range }\end{array}$ & $\begin{array}{l}\text { Lesteral spacing or } \\
\text { spatial wavelength } \\
\text { range }\end{array}$ \\
\hline $\begin{array}{l}\text { 1. Lecalized defect } \\
\text { (ph, scratch, or bump) }\end{array}$ & $\begin{array}{l}0.1 \text { mw }(0.004 \text { in.) to } \\
\text { maximum size of part } \\
(e .8, \text { a large scraich })\end{array}$ & $\mathbf{U}$ & $\mathbf{U}$ \\
\hline 2. Form (contour) & $N / A$ & $\begin{array}{l}\text { U-27 mm } \\
(1.07 \mu \mathrm{in.})\end{array}$ & $\begin{array}{l}100 \mu \mathrm{m}(0.004 \text { in. }) \\
\text { to maximum radius of part }\end{array}$ \\
\hline \multicolumn{4}{|l|}{ 3. Surface rouglwess } \\
\hline $\begin{array}{l}\text { a. D-T surface } \\
\text { (42 } A \text { ras maximum) }\end{array}$ & $N / A$ & $\begin{array}{l}\text { U-0.015 } \mu \mathrm{m} \\
(0,6 \mu \text { in.) }\end{array}$ & $\begin{array}{l}1-100 \mu m \\
(40 \mu i n .-(0.004 \text { in.) }\end{array}$ \\
\hline $\begin{array}{l}\text { 1. Polished surface ( } 10 \text { to } \\
42 A \mathrm{rms} \text { maxiontan) }\end{array}$ & $\mathbf{N} / \mathbf{A}$ & $\begin{array}{l}0,0.035-0.015 \mu \mathrm{m} \\
(0,14-0,6 \mu \mathrm{in.})\end{array}$ & $\begin{array}{l}1-100 \mu m \\
(40 \mu i n .-0.004 \text { in. })\end{array}$ \\
\hline
\end{tabular}

\subsection{METROLOGY CONCEPTS}

The concepts described in the following subsections were developed to meet general and specific metrology requirements described in Sec. 2.1 through 2.3. Concepts are grouped according to whether they primarily relate to localized defects, form (contour) errors, or surface roughness errors.

\subsubsection{Concepts to Identify Localized Defects}

Detection and characterization of macroscopic localized surface defects represents one of the more challenging of the metrology tasks. Since the size, shape, and spatial distribution of surface defects are largely unknown at this time, it is proposed that two area scanning methods be given further detailed study.

For this type of error, which is random, the metrology system used must give a high degree of confidence that no defect of significant size is missed when the part is inspected. Therefore, the inspection must cover the entire surface area, which eliminates random sampling methods.

2.4.1.1 Scanning Scatter Measurement. This measurement has been proposed by $\mathrm{H}$. E. Bennet $\mathrm{t}^{3}$ and is schematically shown in Fig. 2. The instrument would be a large version of the scanning reflectometer now in use at the Naval Weapons Center (NWC), but would be designed for mirrors up to $1.5 \mathrm{~m}$ in diameter.

In the configuration shown in Fig. 2, the mirror to be scanned is mounted on its back on an airbearing track or rotary table. Vibration isolation for the mirror and the air bearing track or rotary table is provided by air pads shown in the lower part of Fig. 2. To meet the focal range requirements of the scanning reflectometer, a flat mirror surface must be translatable (or rotatable) without vertical motion exceeding $15 \mu \mathrm{m}(0.0006 \mathrm{in}$.). The reflectometer optics could be mounted on an additional airbearing track as shown in the upper part of the figure.

When used to inspect curved mirrors, the optics internal to the reflectometer would have to be moved in a programmed motion in the vertical plane so as to maintain a constant distance (within $15 \mu \mathrm{m}$ ) from the mirror surface.

2.4.1.2 Scanning Interference Microscopy. Scanning interference microscopy was developed at LLNL over 15 years ago ${ }^{\prime \prime}$ and has proven very effective for detecting localized surface defects having depths (or heights) as low as $0.1 \mu \mathrm{m}$ ( $4 \mu$ in.). Lateral resolution is limited only by the magnification and the diffraction limit of the optics used. Working distance from the objective to the surface can be extended to as much as 2 in. by the use of extension optics, and the method has been successfully used on flat and spherically curved surfaces.

Figure 3 shows some typical scratch and pit type defects that were photographed with a Zeiss interference microscope. A movie camera was used to record scans across a surface." However, modern high resolution TV systễitis may now be used to record and display the data, depending upon the lateral resolution needed. 


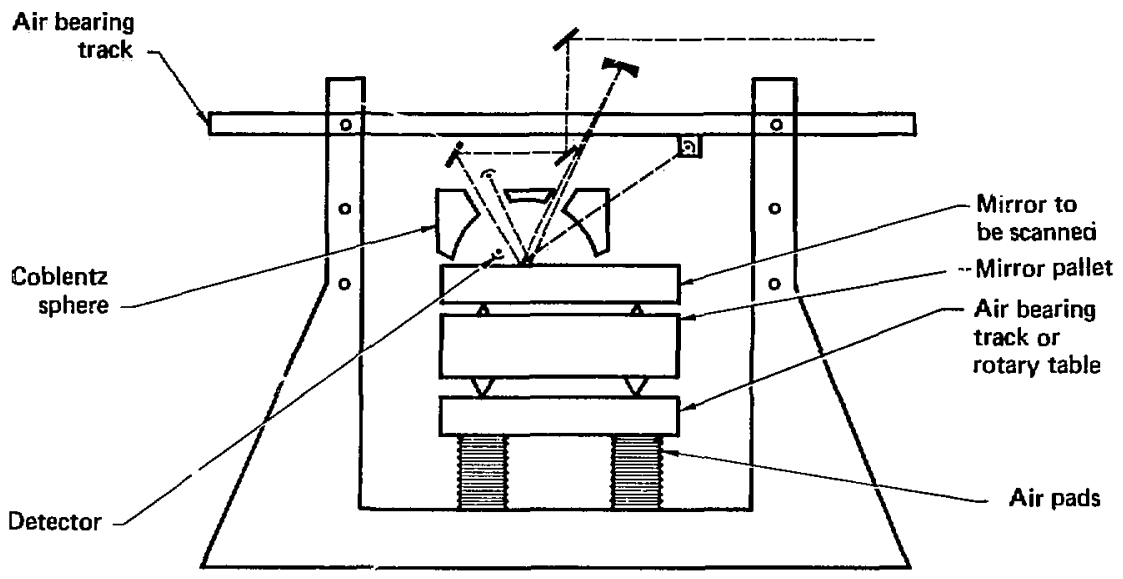

FIG. 2. Concept for a scanning scatter measuring device, from Bennett, Ref. 3.

Figure 4 shows a suggested data record that was developed to classify pits, scratches, and wavelike defects measured on a precision-lapped metal part." The dimensions of each scratch, pit, or wave that is detected is plotted on a grid, which has been divided into zones of severity. Each zone has an associated weighting factor. When all defects have been plotted, a merit index representing the quality of the overall surface can be calculated, based on the number of defects and the weighting factor of each index. Figure 4, in the upper right hand corner, shows how the merit index was culculated for a sample surface.

For HELO applications, weighting factors and the acceptable limits for lateral size, depth (or height), and lateral spacing of localized defects will need to be determined experimentally through extensive laser damage testing, and through analysis of parasitic scattering effects.

There are some practical problems related to the detection and measurement of localized defects when either of the above methods is used. A common drawback to all scatter and microinterferometric techniques is that they have small depths of field and small lateral fields of view. This requires precision movement of the optics (or mirror) and may increase scanning times to several hours for large area mirrors. A major cost component will certainly be the system for recording and analyzing data. Also, since the instrument cannol delect the difference between an actual surface defect and an artifact such as dust, surface cleanliness is of utmost importance and operation in a class 100 clean room will be required.

\subsubsection{Concepts to Identify Form (rontour) Errors}

Surfaces that have rotationa symmetry can be completely described in three dimensions by constructing a "contour map" from an adequate set of radial and azimutt.' measurements. The only practical limits are related to the accuracy of the individual measurements (or sets of measurements), the interval between the measurements along the surface, and the mathematical limits of the system (i.e., digital computer) that synthesizes the contour map from the measured data.

We believe that adequate mechanical and optical metrology must be raloped to meet all the general requirements (see Seu. 2.1) and specific requisements (see Sec. 2.2.2) related to form (contour) errors.

2.4.2. Mechanical Methods. To measure azimuthal errors we propose building the roundness measuring machine as described by Donaldson in Ref. 5, Sec. 2.6.2 (see Fig. 5). 

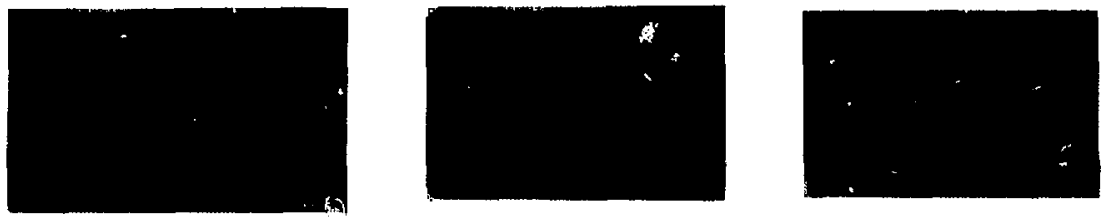

Gage block showing many 5 microinch unidirectional scratches - 80 power, without extension optics.

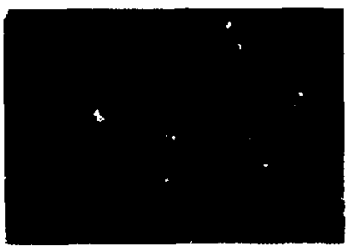

Gage block scratch - 80 power, under extension optics.

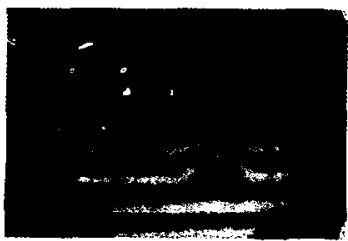

Gage block pit $-\mathbf{8 0}$ power, under extension optics.
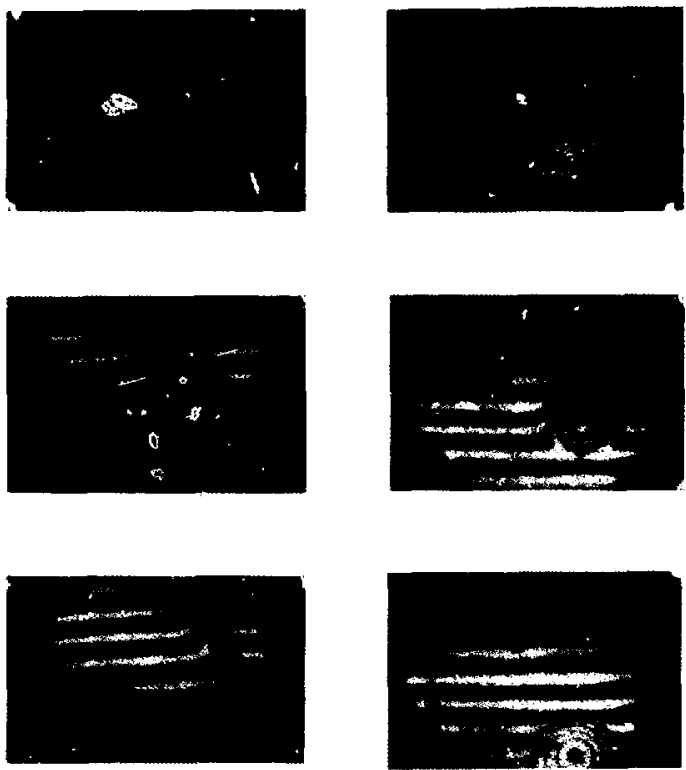

Scratch as seen in scanning sequence.

Peen mark as seen in scanning sequence.

FIi. 3. Scratches and pits photographed with a Zeiss interference microscope. 


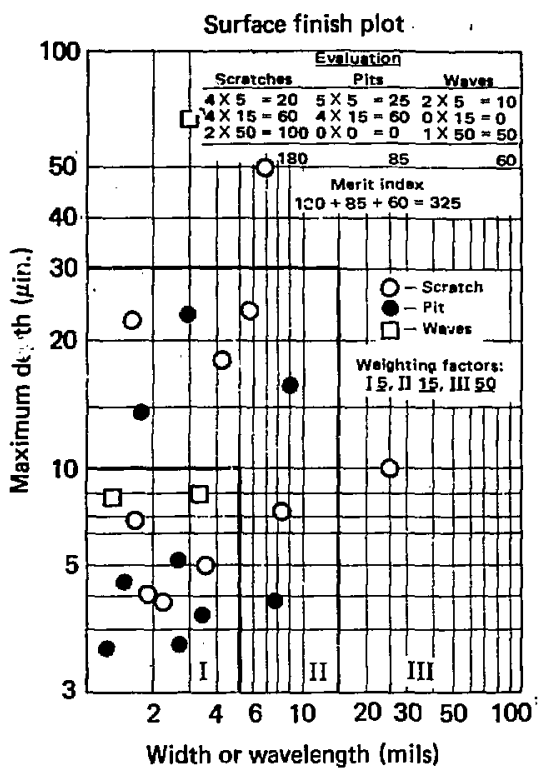

FIG. 4. Suggested data record for evaluating overall quality of optics from measurements of pits, scratches and wave-like defects of the surface.

In his report, Donaldson points out that it is intended that two spindle assemblies (rotor and stator) be built for the LODTM. He continues, "Given a spare spindle and the roundness data collecting and reducing system ... it is attractive to add the framework and drive motor necessary to complete an instrument capable of nieasuring roundness of $1.5 \mathrm{~m}$ ( $60 \mathrm{in}$.) diameter workpieces ... Applications include testing workpiece fixturing methods for azimuthal listortion and measuring the same property for finished workpieces."

Measuring radial errors using the LODTM itselt, as described in Ref. 5, Sec. 3.20, offers an attractive, economical approach to obtaining this data. The tisulting radial $(X)$ and axial $(Z)$ errors are expected not to exceed $30.4 \mathrm{~nm}(1.22 \mu \mathrm{in}$.) and $32.0 \mathrm{~nm}$ (1.28 $\mu$ in.) P- $\mathrm{V}$, respectively.

The drawback of using the LODTM to measure its own product is that it could have a significant undetected repeatable error. This draw- back will be overcome if adequate and separate optical measurements are made prior to the start of polishing.

2.4.2.2 Optical Methods. Two interferome tric methods are presented as candidates for further evaluation. Both methods are adaptable to testing optics as mounted on LODTM or on a controlled polishing machine (CPM).

\subsection{Full Aperture Phase Measuring} Interferometer. This interfercmetric method, shown in Fig. 6 and Fig. 7, was proposed recently by the Perkin-Elmer Corporation ior use at the Advanced X-Ray Astrophysical Faciitty (AXAF) for NASA and at the Smithsonian Instituie Astrophysical Observatory. ${ }^{12}$ The method is applicable to testing waxicons or reflaxicons, but only if the inner and outer cones are fabricated as separate pieces, in contrast to the one piece construction shown in Fig. 1.

As shown in Fig. 6, the helium neon laser is used as a light source in a phase measuring Twyman-Green interferometcr. The test configura- .tion is designed in such a way that the inner cone of the waxicon is replaced by a beam expander system and a test cone, and thereby a double-pass test of the outer cone of the waxicon is possible. An alternate concept to test the outer cone with a simplified beam compactor is shown in Fig. 6A. Once the outer cone has been tested, the inner cone can be properly positioned and the waxicon tested as a unit, as shown in Fig. 7. Advantages of this full aperture testing method include high sensitivity and availability of data that simultaneously relates one given point to every other point in the entire aperture.

Three limitations should be noted. First, the method is applicable only to waxicons constructed as separate elements. Also, the conical beam expander may be difficult to fabricate and accurately lest as a separate unit. Finally, double-pass ref:ection of a D-T surface (before polishing) sometimes significantly lowers resolution of the centers of the fringes, thereby complicating the data reduction task. However, the simplicity of use and the prospect of getting a visual display of a full aperture interferogram make this scheme a viable candidate for optical testing.

The computer output associated with this method can be in the form of surface contours of the test element, or the actual wavefront distortion produced when both the inner and outer waxicon cones are tested together. 


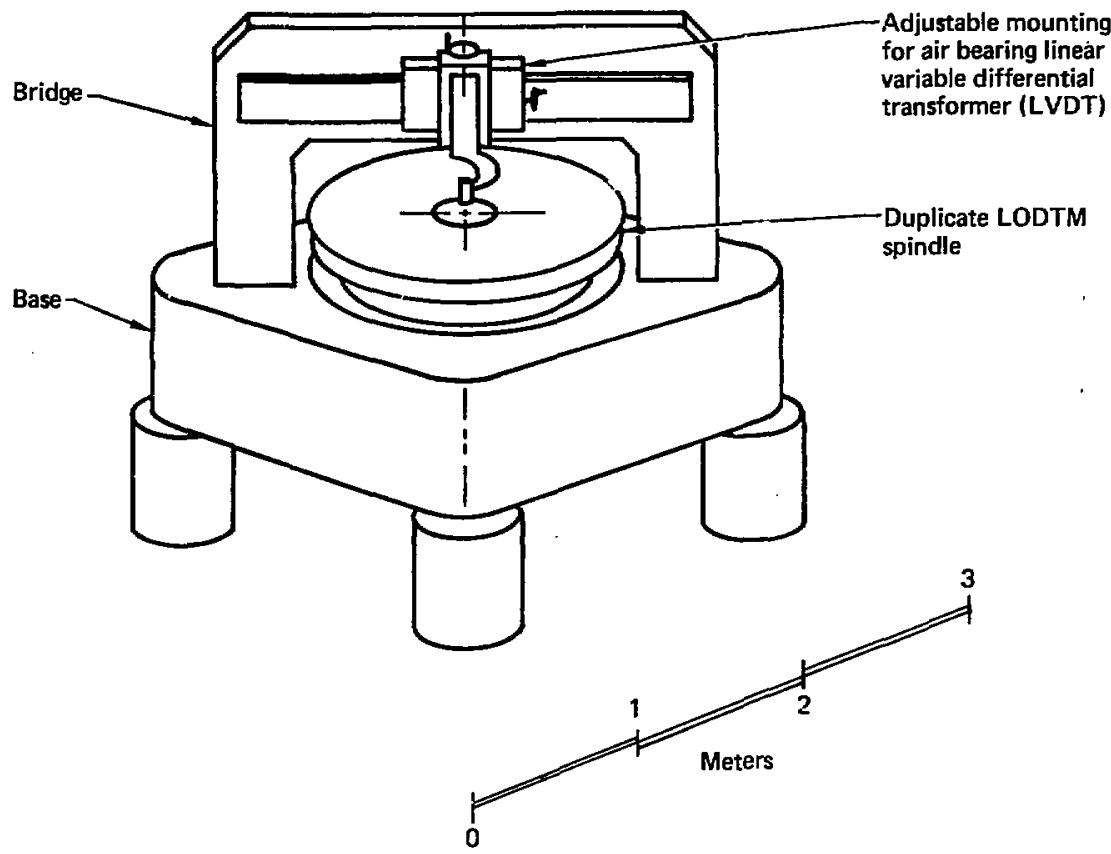

FIC. 5. Conceptual drawing of an instrument that uses a duplicate LODTM spindle for measuring roundness of HFLO.

A second interferometric technique using holographic optical elements (HOE) and a geometry similar to the one shown in Fig. 6 may also be possible. Here the cone compensator, which is a re atively difficult optical element to manufacture and test, could be replaced by a computer generated hologram that contains not only the linear phase shift provided by the cone, but also the spherical aberration correction obtained from the compensator. This has the distinct advantage of providing a testing device whose accuracy is totally based on the positional accuracy of the fringes in the holographic element, and in the number of those fringes. As a result, the holographic test element, once generated, has an accuracy independent of the optical fabrication technology and is very inexpensive to duplicate.

2.4.2.2.2 Radial Scan Interferometer. The :- terferometer as shown in Figs. 8A and $8 \mathrm{~B}$ is a modified
Mach-Zehnder type where light is reflected once from the test surface(s) and collimated (in the plane of the figure only) using a spherical lens. This concept is being used by the Itek Corporation for measuring parabolic and hyperbolic contours of revolution of $x$-ray telescopes being fabricated for the AXAF Program. ${ }^{13}$

When properly aligned, the image plane interferogram consists of a narrow band of fringes that appear in a plane normal to the figure. On either side of this narrow band, the fringes rapidly diverge or converge as the reflected wavefront warps out of the plane of the figure. With the configuration shown in Fig. 8A, a narrow band interferogram representing a single radial profile of the waxicon inner cone is imaged on the self-scanned linear photodiode array. If the waxicon is shifted to the left (Fig. 8A) so that the collimated beam from beam splitter $\mathrm{BS}_{1}$ is incident on the outer $c_{\ldots} \mathrm{e}$ 


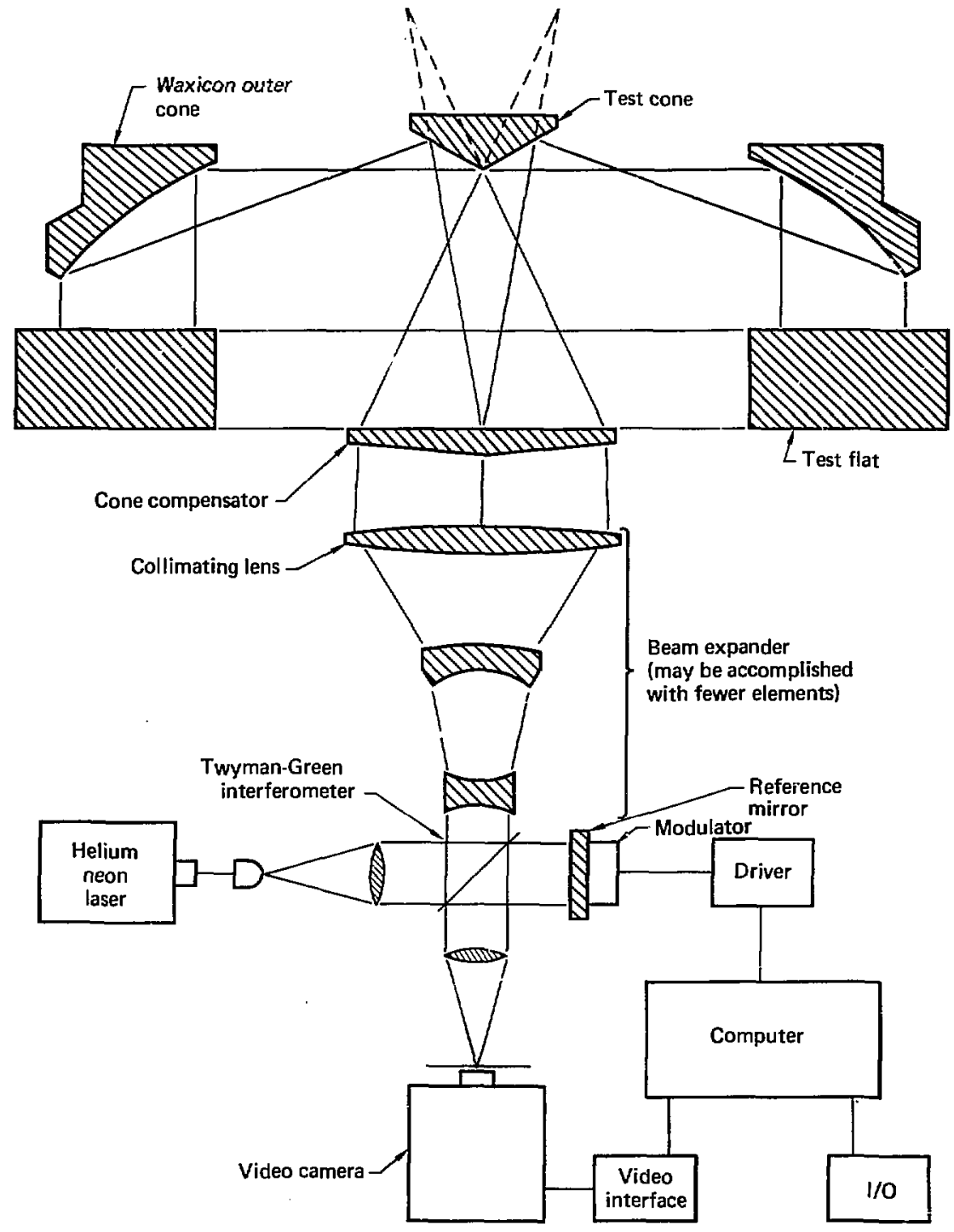

FIG. 6. Concept for testing the outer cone of a waxicon by using a test cone. 


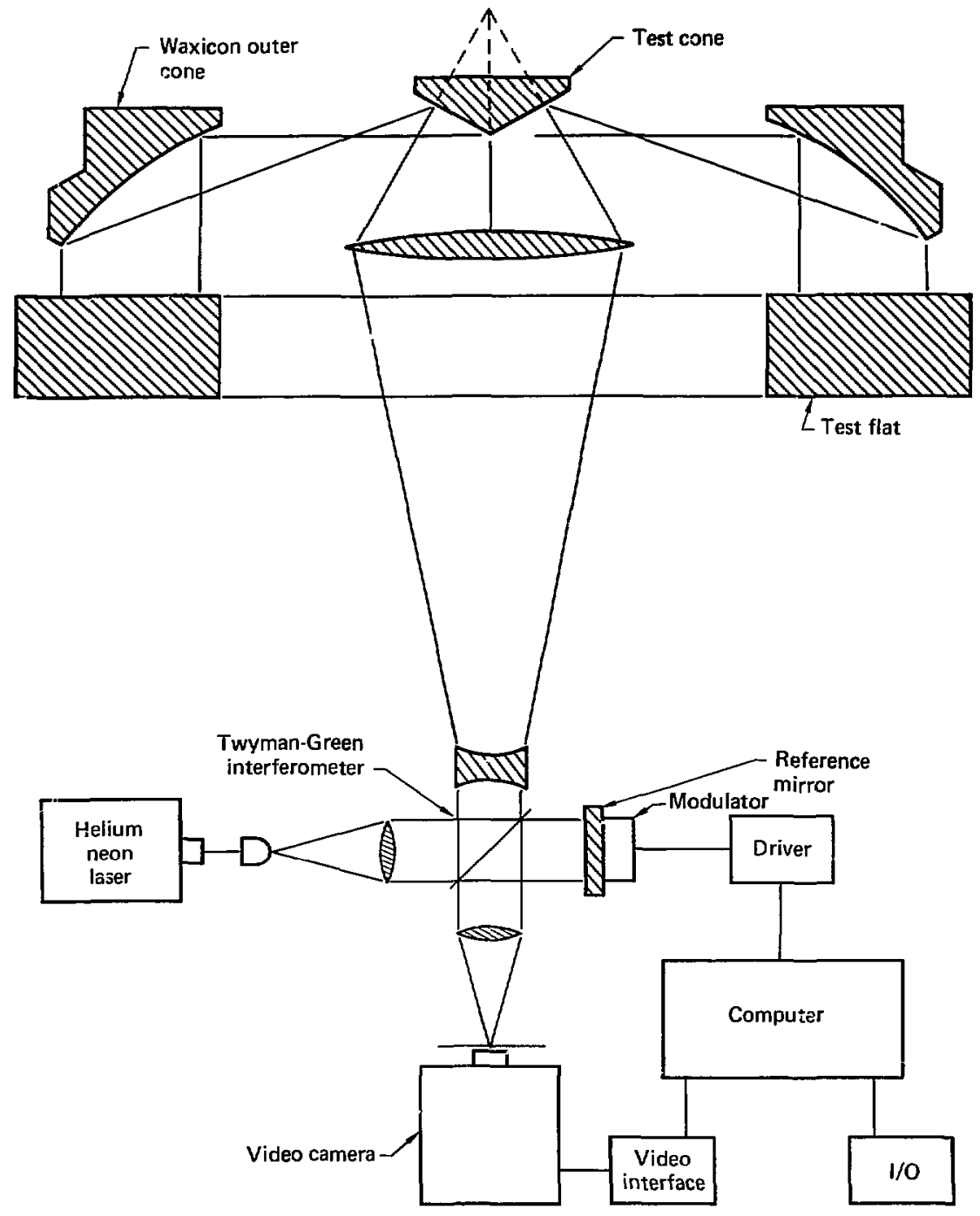

FIG; 6A. Alternate concept for testing the outer cone of a waxicon by using a test cone. 


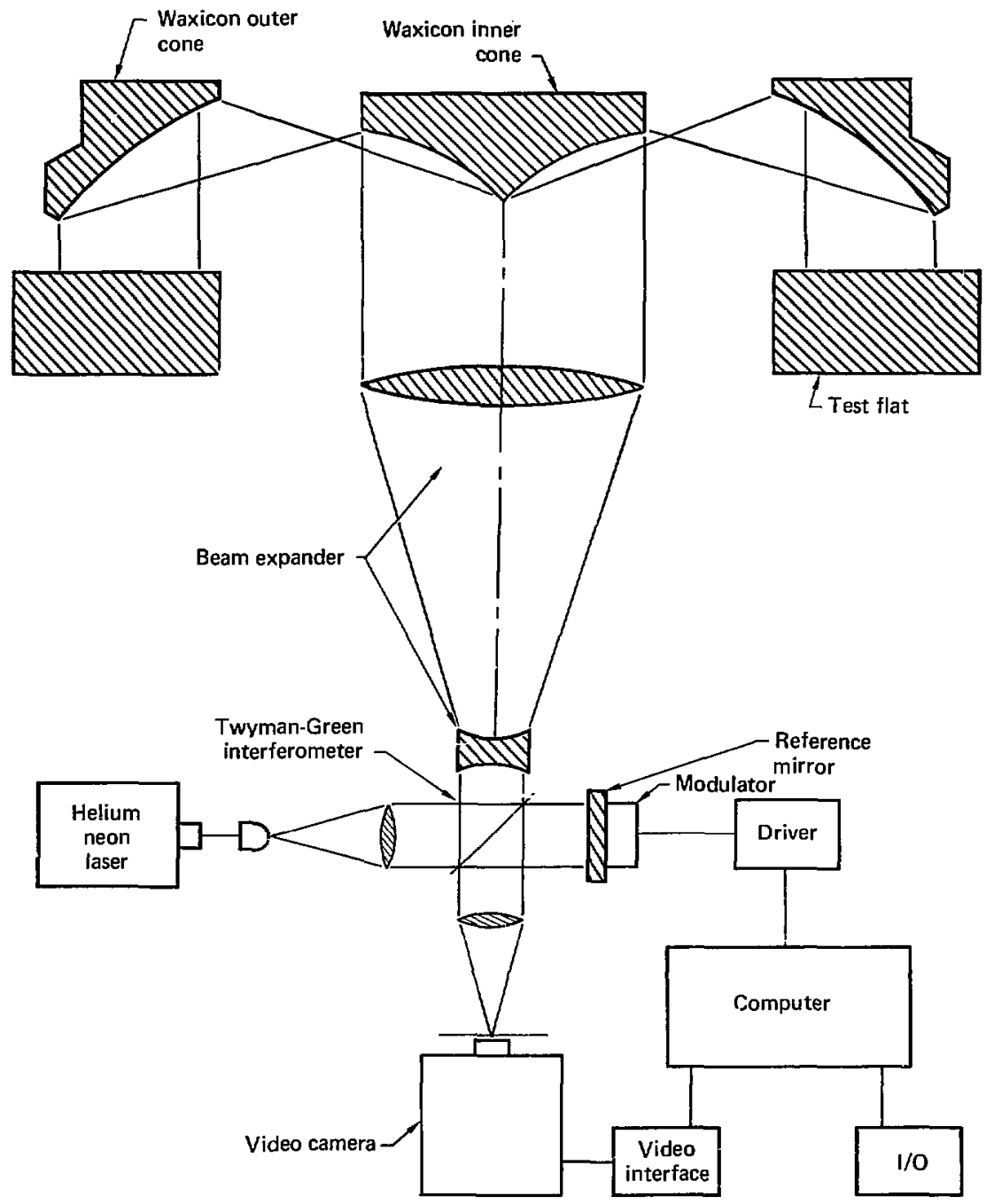

FIG. 7. Concept for testing a waxicon system consisting of both an inner and outer cone. 

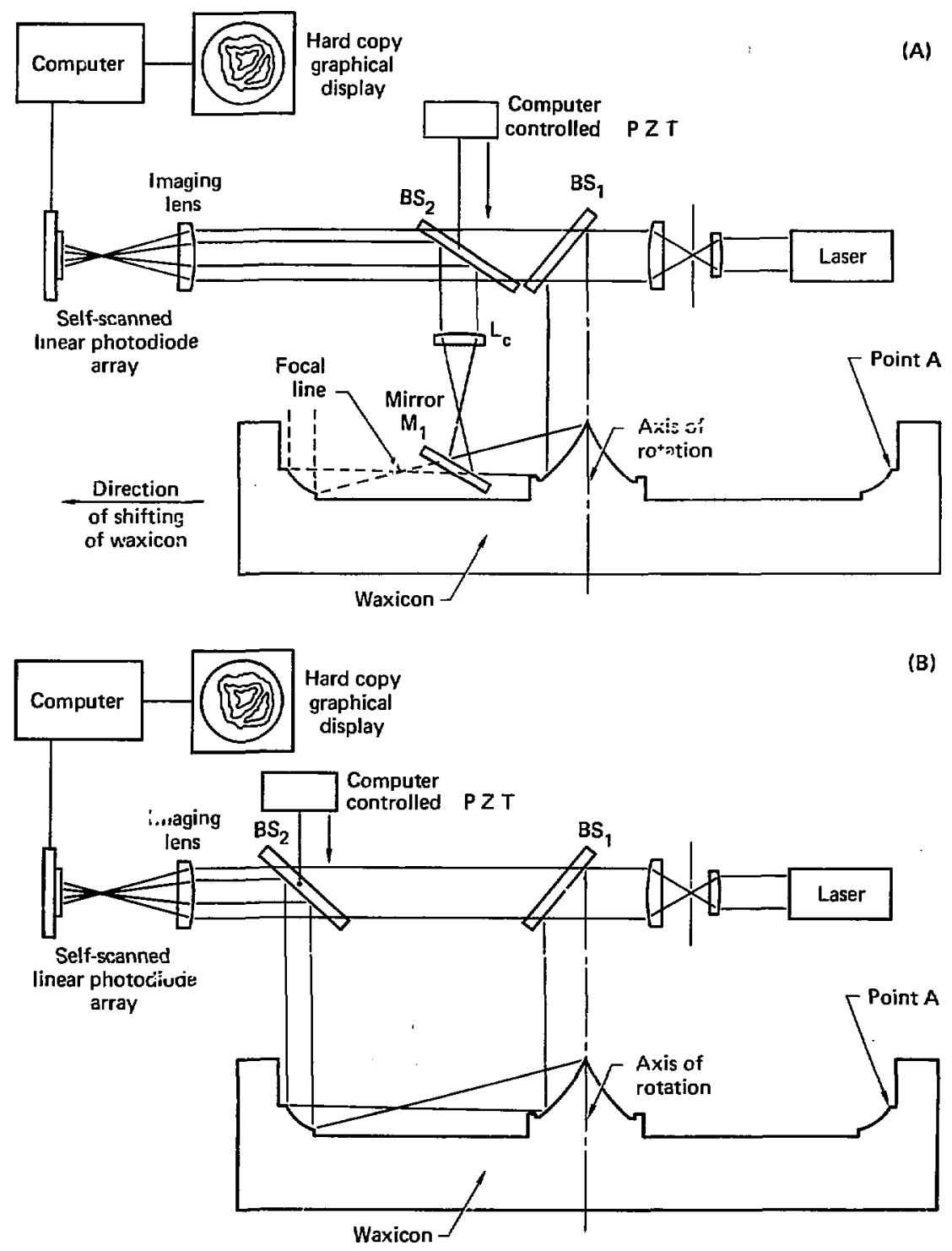

FIC. 8. Concepts for radial scan interferometer systems. The system in $(A)$ is designed to produce a single radial profile of a waxicon inner and outer cone. The system in (B) is designed to represent the combined profile of an inner and outer cone. 
surface in the vicinity of point $A$, and mirror $M_{j}$ is properly adjusted, a radial profile of the outer cone can be obtained. Rotating the waxicon about its axis will provide data from which a contour map of the entire surface can be generated.

If the interferumeter is set up as shown in Fig. $8 \mathrm{~B}$, a narrow band interferogram representing the combined profile of the inner and outer cone is obtained. Thus, the inner and outer cones can be tested separately, or in combination, even if the waxicon is constructed as a single piece, provided sufficient space is available tc place mirror $M_{1}$ near the focal line of the two surfaces (Fig. 8A).

The main advantage of this interferometric method is that all auxiliary optical components are either flat or spherical, and have small diameters. The configuration is very flexible, and the system should he easy to set up and align. The computer and data reduction system rcpresent the main cost of the test set-up.

The main disadvantages are that there must be complete reliance on the computer analysis and synthesis system to provide an accurate contour map, and an accurate (air bearing) spindle must be provided to rotate the part. However, the interferometer can be "calibrated" using linear conical test pieces whose characteristics have been accurately defined by other methods.

The interferometers shown in Figs. 6, 6A, 7, 8A and $8 \mathrm{~B}$ are known as phase measuring interferometers (PMI). In this type of interferometer the intensity at each photodiode in the linear array is read into the compter, as the computer controlled piezoelectric transducer (PZT) steps a beamsplitter or reference mirror through increments of one wavelength of optical path. With the use of synchronous detection, the surface form or contour can be calculated.

Some important advantages of a PMI over conventional ty pes of interferometers are that a PMI will give greater accuracy and will provide real time data analysis. The real time data analysis can include isometric and plane contour mapping with varial'a contour sensitivity, array subtraction, surface calibration, time averaging, and deconvolution of wavefront data to yield aberration coefficients.

At Perkin-Elmer Corporation, several PMI are used in a production environment for testing highquality reflecting spheres, flats, mirrors, and refractive elements. A measurement uncertainty of less than $0.01 \lambda$ peak-to-valley and $0.001 \lambda \operatorname{rms}$ (for $\lambda=$ $6328 A$ ) has been achieved in evaluation of a large spherical reflector. 14

\subsubsection{Concepts do Idisibify Suriance Roughness Errors}

2.4.3.1 General. A number of techniques have been used to measure surface microtopography (or microroughness) including optical or electron microscopy, FECO (fringes of equal chromatic order) interferometry, diamond stylus profilometry, and indirect methods such as scattered light. ${ }^{9}$ Each method has a different lateral and/or height range. Lateral ranges are normally from a micrometer to a few millimeters,

Because of these limited lateral ranges, surface microroughness measurements must be regarded as sampling techniques enly, for all sizes of optics of interest here. Most if not all the techniques listed above have been successfully used on small (i.e., a few centimeters in diameter), flat, sample pieces only. Very few would be adaptable to direct surface measurement of actual optical components.

One approach to circumventing the problem of accurately sampling the microtopography of large size optics has been through the use of surface replicas. Replicas have been used with limited success by Parks, ${ }^{15}$ H. E. Bennett ${ }^{16}$ and others. ${ }^{17}$ The primary questions that remain unanswered are:

1. How accurately does the replica reproduce the microtopography of the actual surface?

2. How can the replicas be supported after removal from the surface so they will retain the original surface contour within reasonable limits?

Instruments, or roughness sensors, related to ihe following measurement methods could conceivably be mounted on the LODTM tool bar and, if accurately located relative to fixed radial $(X)$ and vertical ( $Z$ ) positions, used to measure the surface microtopography over short radial travels, and over 360 degrees of travel in azimuth. They could also be used on the roundness measuring machine (Fig. 5), primarily for azimuthal scans.

2.4.3.2 Scanning Scatter Measurement. The scanning scatter measurement method described in Sec. 2.4.1.1 and shown in Fig. 2 would probably work well for D-T and polished surfaces. If an additional detector track is provided normal to the main (radial) track, directional scatter could be measured as well as total integrated scatter (TIS). 
The former may be an important tool for diagnosing potential LODTM operational problems.

If a helium neon laser is used for a light source, the resolvable height range derived from scatter measurements is about $10^{-5}$ to $10^{-1} \mu \mathrm{m}(0.004$ to 4 $\mu$ in.). Lateral range is about $110100 \mu \mathrm{m}$ (40 to 4000 $\mu$ in.). ${ }^{18}$

2.4.3.3 Heterodyne Surface Profiling. The Heterodyne Surface Profiler (HSP), shown in Fig. 9, was developed at LLNL and has been in routine use for over a year to measure surface microtopography of optically polished flats. ${ }^{19}$ A good correlation was found between measurements made on the HSP and those made on the same sample by J. M. Bennett ${ }^{19}$ at NWC, China Lake, CA using stylus profilometry. The HSP has a height sensitivity range of plus or minus $1 A\left(10^{-4} \mu \mathrm{m}\right.$ or $0.004 \mu \mathrm{in}$.) to $0.6 \mu \mathrm{m}$ (24 $\mu$ in.).

The operating principle of the HSP is based on a common path heterodyne interferometer in which two orthogonally polarized beams of slightly different frequency are focused on the surface to be measured. One of the focal points acts as a reference while the other point circularly scans the surface. The phase of the beat frequency of the interfering return beams is directly proportional to the surface height difference of the two reflected beams. From this measurement the surface profile, autocovariance function, spectral density function, and height and slope distribution functions are calculated automatically by the computer.

The HSP can be used on D-T or very sraooth polished metal or dielectric surfaces. Lateral resolution is limited to the distance between the two focused spots, which is about $100 \mu \mathrm{m}$ ( 0.004 in.) for the present instrument. For this reason the HSP is more suited for roughness measurement of highly uncorrelated surfaces (i.e., polished surfaces) than it is for surfaces that are highly correlated (i.e., grooved surfaces resulting from single-point diamond turning).

2.4.3.4 Stylus Profilometry. Diamond stylus profilometry has in recent years become one of the most useful tools employed to measure microtopography of smooth optical surfaces. 20 Because of

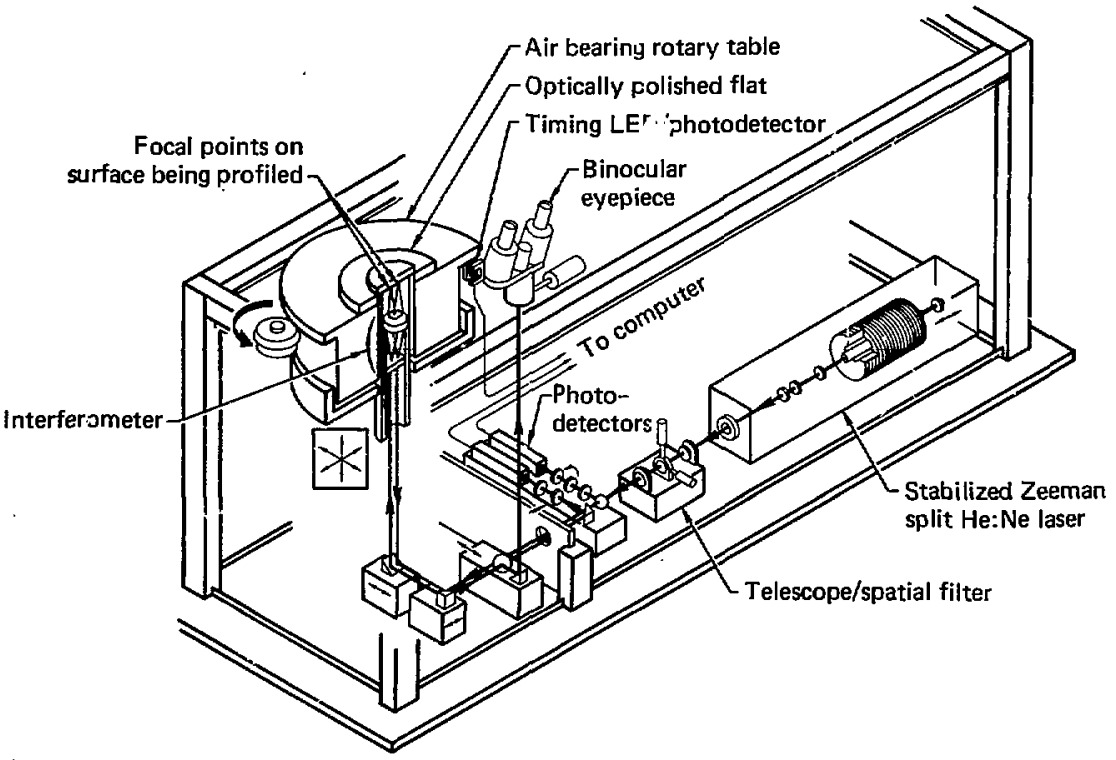

FIG. 9. Optical layout of the heterodyne surfuce profiler. 
the ease of use and convenience of data reduction, stylus profilometry has largely replaced FECO interferometry for optical surface microtopography.21

When the stylus is used with a $1-\mu \mathrm{m}(40 \mu \mathrm{in}$.) diameter tip, the height range has a lower limit of about $20 A(0.002 \mu \mathrm{m}$ or $0.08 \mu \mathrm{in}$.$) , and the upper$ limit is determined by the maximum motion of the stylus transducer (about $2500 \mu \mathrm{m}$ or $0.10 \mathrm{in}$.). With this same diameter tip, the lower limit of the lateral range is $0.5 \mu \mathrm{m}\left(20 \mu \mathrm{in}\right.$.). ${ }^{18}$

Recently J. M. Bennett has shown that by using a wedge shaped tip with a minor (flat) dimension of $0.01 \mu \mathrm{m}(0.4 \mu \mathrm{in}$.$) , the lower limit of the lateral$ range can be reduced to less than $0.025 \mu \mathrm{m}$ (1 rin.). 22

\section{CHAPTER 3. DISCUSSION OF POLISHING METHODS}

\subsection{GENERAI, DISCUSSION}

The polishing of glass or metal is based on the principle of wear of materials by abrasive materi $! s$, or laps. In the case of classical optical polishing, a lap is placed against the surface of the material to be polished and moved about. The energy inparted to the surface by the lap, actin $n_{\mathrm{k}}$ through some undetermined combination of methanical abrasion, chemical attack, and thermal flow, disrupts the material and changes the surface microroughness. The polishing process is known to be more than just a surface phenomena. It leaves inherent subsurface damage and chemical alterations to the near surface region of ariy material. The characteristics of the optical surface desired must be specified, as well as possible, before any sound process can be developed to produce that surface.

Classically, optical polishing processes have been developed through experience and are empirical in nature. Conventional processes produce surfaces that have, to date, been satisfactory in terms of shape and finish required. The processes, however, do not lend themselves well to quantitative, repeatable generation. of complex or aspherical shapes, because the material actually worn away by the process varies from point to point, while the process is characterized by the average of material worn away over an area. To date, this area-averaging relationship has been best described by a general equation by Preston that assumes that, at any point, the thickness of material removed by polishing is proportional to the relative tool velocity, pressure, and time, or;

$\mathrm{dh}=\mathrm{KVPdt}$, where

$$
\mathrm{dh}=\text { thickness of material removed }
$$

$$
\begin{aligned}
\mathrm{V}= & \text { relative velocity between the lap and } \\
& \text { the point on the surface, } \\
\mathrm{P}= & \text { local pressurc at that point, } \\
\mathrm{K}= & \text { wear constant or constant of propor- } \\
& \text { tionality, and } \\
\mathrm{dt}= & \text { time. }
\end{aligned}
$$

Experience has shown that while this relationship is generally correct it is clearly not complete or detailed enough to allow repetitive deterministic generation of specific optical surface shapes. A number of systems generated at the University of Arizona. the Itek Corporation, and the Perkin-Elmer Corporation, which are based on Preston's equation, have shown that aspheric shapes can be generated using this mathematical model, but not to the deg:ee of repeatability that will be required in the optics of interest here. The result is that any lapping process based on Preston's model, and whose goal is a specific shape, will at best be iterative.

A closer examination of the optical polishing process reveals that while Preston's equation is generally correct, the constant of wear is not universally constant but ieflects a complex interrelationship of a number of variable facters involved in a specific polishing process. While all of these factors affect the finish of the surface as we!l as its contour, we will restrict the discussion to contour, at least for the moment.

Figure 10 shows relationships between the shape of a precision surface and factors involved in the classical polishing process, as originally put forth by Kuznetzov. 23 This figure indicates some 30 factors that are known to effect the polishing process. Even though this representation does not give a complete picture, it adequately portrays the complexity of the process, and points to a possible 


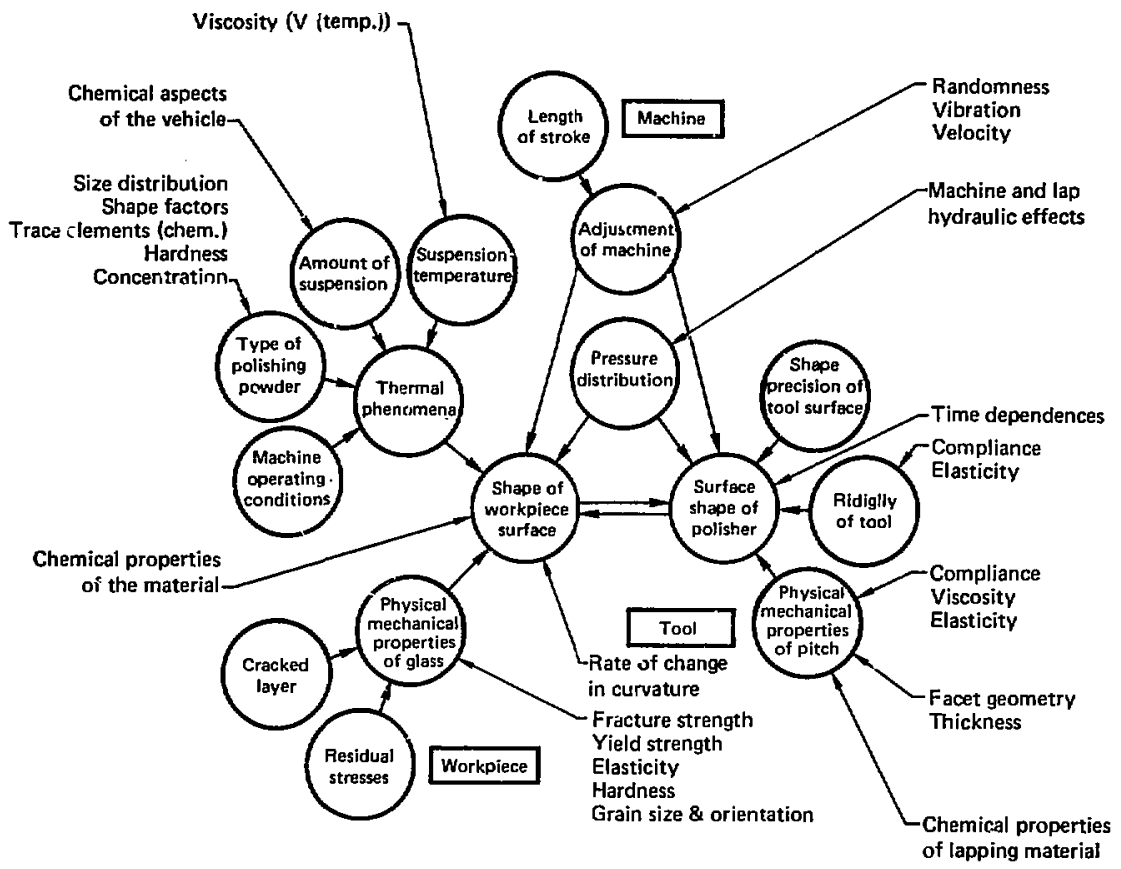

FIC. 10. Relationships between factors in the classical polishing process and the shape of the surface being polished, from Kumanin, Ref. 23.

direction for making Preston's equation fit reality more closely. It also points to a number of previously uncontrolled parameters in the polishing process that must be controlled if the high accuracies requirct in resonator optics are to be achieved.

The precision and geometry of the Alpha Laser optics clearly indicate a CNC polishing process will be required. For that process to be adequate, two things are necessary. First, the model used for predicting and controlling the motion of a lap, whose character must be very well known, will have to depend on most, if not all, of the parameters listed in Fig. 10. The more parameters that can be contralled, the more accurate the prediction of the model and hence the more accurately the optical surface can be controlled. Second, the model will require data input from a controlled process whereby the difference between the desired surface and the actual surface (i.e., the total amount of material to be removed) will be available. Such information implies an integrated metrrlogy system of some form, either an optical, a mechanical, or a combination system, that is sensitive to the smallest surface feature of importance.

The polishing "machine" can be divided into two main compunents, the polishing head that provides the wear function, and the remainder of the machine that positions and moves the polishing head in a controlled manner.

\subsection{ADDITIONAL CONSIDERATIONS FOR POLISHING DIAMOND- TLRNED OPTICS}

In Sec. 2.2.3 (Surface Roughness Errors) it was pointed out that $D$-T surfaces have a periodic structure. A grooved structure can have significant 
detrimental effects on absorption, scattering, and threshold of laser damage, depending upon the periodicity and depth of the grooves, wavelength of the incident radiation, angle of incidence, plane of polarization, etc. $3,9,10$ Recently, Chodzko et al. have shown experimentally that surface properties of D$T$ conical or waxicon reflectors can produce significant polarization effects within an annular gain (HSURIA) resonator. ${ }^{24}$ They measured single surface reflectivities of azimuthal and radial polarizations and found differences of about $3 \%$ for an incident wavelength of $10.6 \mu \mathrm{m}$. Because the rays strike six diamond-turned surfaces per round trip in the resonator, the reflectivity difference $\left(\mathbf{R}_{\mathbf{s}}>\mathbf{R}_{\mathbf{p}}\right)$ provides a strong selector for the azimuthally polarized mode.

Polishing or "smoothing" of the Alpha Laser D-T optics may be neeessary to:

1. Reduce surface scatterine, absorption, and reflectivity difference between $S$ and $P$ polarizations.

2. Reduce medium-to-low spatial frequency slope errors produced by diamond turning (see Refs. 6, 7).

3. Reduce reflective wavefront distortion for a combination of components as used in a system.

4. Accomplish some combination of all three above.

Careful experimental evaluations (including those of laser damage) must be made of the properties of D-T metal surfaces as they are projected to be finished on LODTM, and later coated, before it con be determined whether polishing appears to be necessary and/or desirable.

As the diamond turning technology itself is a relatively new one, and particularly with respect to optical components, there is little experience in polishing of diamond-turned optics. Some work has been done at LLNL, the University of Arizona, and a few other places in the country. Most of the work indicates that we understand very little of the process or sequence of physical events that occurs when diarrond-turned metal surfaces are polished. Nevertheless since 1975 at LLNL, precision $x$-ray microscopes (Wolter type) with electroless nickel surfaces have been diamond-turned to accuracies of $1 / 4$ to $1 / 2 \mu \mathrm{m}$ (10 to $20^{\circ} \mu \mathrm{in}$.) and polished to a microroughness of $10 A\left(10^{-3} \mu \mathrm{m}\right.$ or $0.040 \mu \mathrm{in}$.) rms, 25
Optical engineers do not agree as to how much material must be removed from a diamond-turned surface before reaching an optical surface free of all errors except those from the lapping. The implica- . tion is that the diamond turning process itself may produce subsurface damage (i.e., crystal dislocation, densification, microcracking), or other mechanical phenomenon. Some research and experimentation may be required before a good estimate can be given as to the total amount of material to be removed in the polishing process.

All of the information given earlier about the polishing process was related primarily to glass, although almost everything applies equally well to metals. The differences in mechanisms between the polishing of glass and metal, however, are not well known. The same three mechanisms, that of thermal flow, chemical attack, and mechanical abrasion still occur; at least that's the consensus. It is clear, however, that the nature of the chemical attack and abrasion will be considerably different because the relationships between the fracture stress, the yield strength, and the elasticity of the materials are quite different. Our empirical understanding of how these processes affect metals is not nearly as far along as for glass. Hence, the degree with which the polishing of metals can be predicted and repeated will probably not be as good. This isn't to say that metal surfaces of the quality currently required cannot be achieved; it just says they might not be as easy to obtain as glass surfaces would be.

\subsection{POLISHING HEAD CONCEPTS}

3.3.1 Fluid Bearing Belt Lap. The fluid bearing belt lap, shown schematically in Fig. 11, is a variation of a technique used at LLNiL for the last five years for polishing single-point diamond-turned (SPDT) metal surfaces. At present we are using elastically-backed, pitch-beeswax laps in which diamond particles as small as $1 / 10 \mu \mathrm{m}(4 \mu \mathrm{in}$.) are embedded, up to 80 to $90 \%$ of their diameter, in the pitch. Silicon oil is the most common lubricant used. This basic technique has produced very smooth surfaces in SPDT electroless nickel flats (3 in. in diameter) having microroughnesses of $10 A$ $\left(0.001 \mu \mathrm{m}\right.$ or $0.04 \mu \mathrm{in}$.) rms or less, ${ }^{26}$

In order to extend this polishing method to accommodate aspheric surfaces of revolution, we propose the development of a polishing head, 


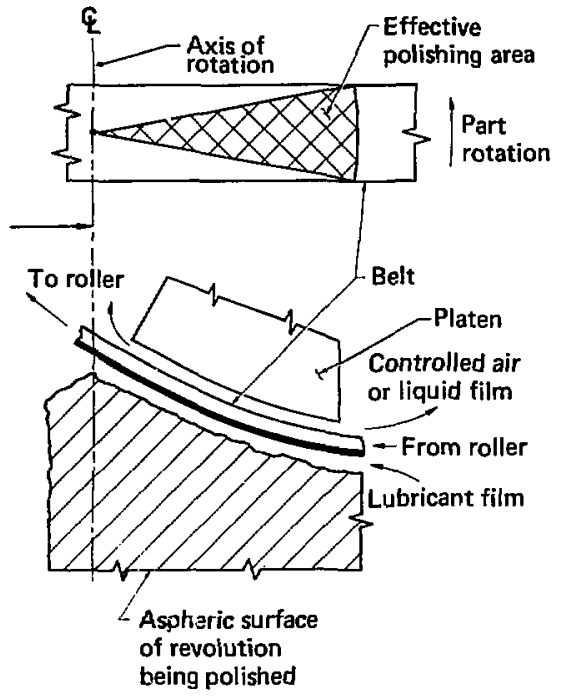

FIG. 11. Concept sketch for a belt lap for polishing HEL.O. Two controlled fluid films, one on each side of the belt. provide precision polishing.

shown schematically in Fig. 11. This method uses a thin, tensioned, flexible belt, that is impregnated with diamond abrasive and that moves transverse to the SPDT grooves in the surface. The belt will be backed up with a precision SPDT porous platen, separated from the belt by an air or liquid film, having a shape precisely matching that of the zone to be polished (allowing for the belt and fluid film thickness). The part being polished will be mounted under the belt on a good quality spindle and rotated slowly about its axis of rotation.

The belt will be vary thick with respect to the microgroove height and period so it will first bridge the high spatial frequency peaks and then contact the lower spatial frequency "waves" under slightly increased pressure. An air or liquid film of controlled thickness will separate the back of the belt from the precision machined porous bearing surface on the platen. A second lubricant film, controlled both in flow rate, and viscosity, will keep all but the very tips of the abrasive diamond particles from contacting the surface of the part. Gradual relief of the platen edges will define the polishing zone boundaries, and will produce a wedge shaped contact a.ea as shown in Fig. 11. Controlled variables include lubricant film interface properties, belt speed, rotational speed of the part, and contact pressure-all of which may be varied from zone to zone.

A different shaped platen will need to be machined for each zone to be polished, and overlapping the zones in the radial direction will probably be desirable. The amount of overlap used will depend on the rate of change of curvature in the radial direction.

\section{3,3.2 Roller Lap}

Sume form (contour) errors of relatively long spatial wavelength may remain after smoothing with the fluid bearing belt lap described above, even with considerable overlapping of radjal zones. Remaining form (contour) errors and any residual roughness could be smoothed out using a roller type of lap shown in end view in Fig. 12.

The roller will be cylindrical or i. ? ? shaped, made of elastic material similar to that of the belt lap, and pressurized with a bigh viscosity fluid that has been heavily damped with particulates such as phenolic microballoons or graphite powders. The roller will rotate about ar: axis set at a

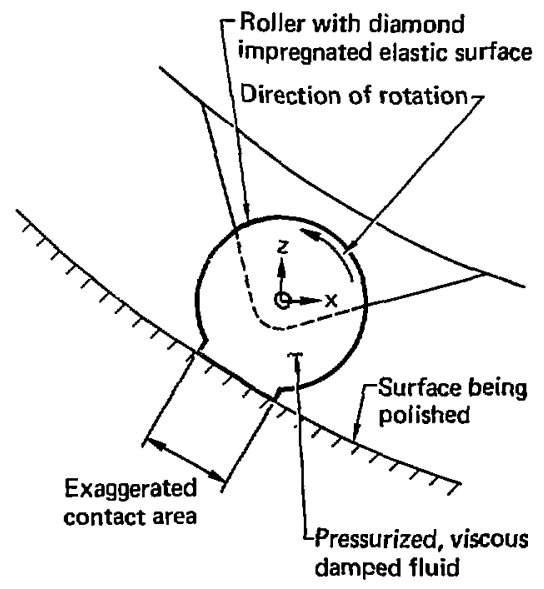

FIC. 12. Concept for a roller lap for polishing HEIO. 
fixed angle (not necessarily a right angle) relative to the plane containing the axis of rotation of the part and the local surface normal. The part will be rotated slowly about its axis of rotation while the rotating roller lap is moved, with controlled axial $(Z)$ and radial $(X)$ motions, to follow the contour of the part.

Elasticity of the roller material and programmed positioning will create a spot contact rather than a wedge shaped contact tirea, as in the case of the belt lap. A lubricant film will again be used, with controlled motion and pressure regulating the amount of material removed.

Either the belt Jap and roller lap could be used for localized surface smoothing and figuring if the rotation of the part is stopped. Wcar functions (values of the constant $K$ in Preston's equation) could be determined for both laps by experimental polishing of precision machined (SPDT) cylinders and conic surfaces of revolution.

\subsection{PO:.AR POI.ISHING MACHINE}

The seven degrees of motion and their required magnitudes shown in Fig. 13 cover all possible requirements for polishing aspherics of revelution of the type used in the Alpha Laser program. A machine similar to that shown in Fir. 14 would provide controlled positioning and motion of the polishing head. For CNC of the polishing process, only the three axes (2), (4), and (5) need be included under computer control.

The polishing head shown in Figs. 13 and 14 is a conventionai type (it coulc be used for spot polishing) with the spindle rotational axis (1) shown normal to the two spindle tilt axes (2) and (3). If the fluid bearing belt lap (Sec. 3.3.1) is used, the linear motion of the belt would take the place of spindle rotation (1). If the roller lap is used (Scc. 3.3.2), roller rotation about its own axis would take the place of spindle rotation (1).

When using a roller lap, vertical travel (4) in Fig. 14 would provide $Z$-axis travel and carriage travel (5) (Fig. 14) would provide X-axis travel (Fig. 12). Rotation of the part being polished is provided by rotating the table (7). Bridge rotation (6) (Fig. 14) would be needed only if dynamic pressurization of the part is necessary during the polishing process, and it is not practical to use cooling fluid rotary couplings.

If the need for the bridge rotation (6) could be releted, the resulting six-axis polar polishing ritachine could probably be huilt using the base and CNC of a commercially available vertical-axis machine tool. Positional repeatability and accuracy of this type of machine are well within requirements set for a polar polishing machine (i.e., 25 to $50 \mathrm{\mu m}$ or 0.001 to 0.01 in.) because maintaining eonstant or controlled pressure between the lap and the surface to be polished will be accomplished primarily by a "soft spring" mounting between the polishing head and the spindle mount. The main construction requirements are that the machine be rigid, free of vibration, and thermally stable to within the aforementioned tolerance.

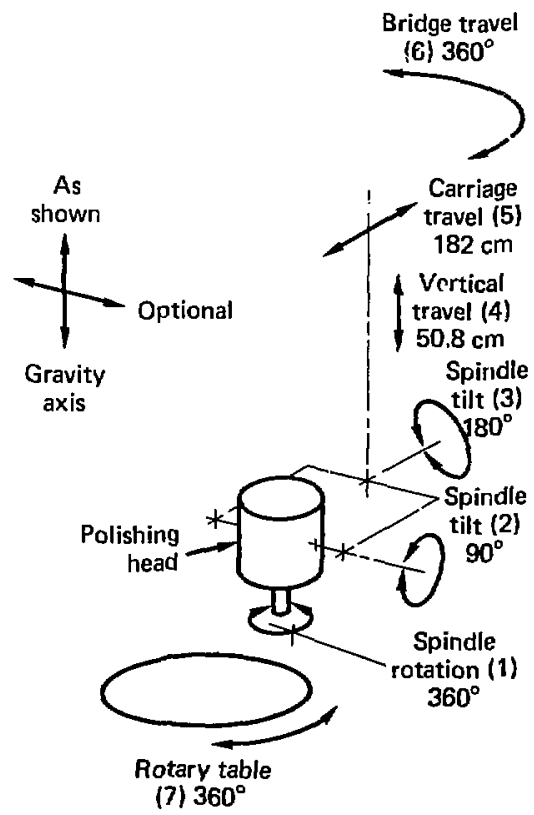

FIG. 13. Axis diagram showing the seven degrees of freedom needed for a polar polishing machine. 


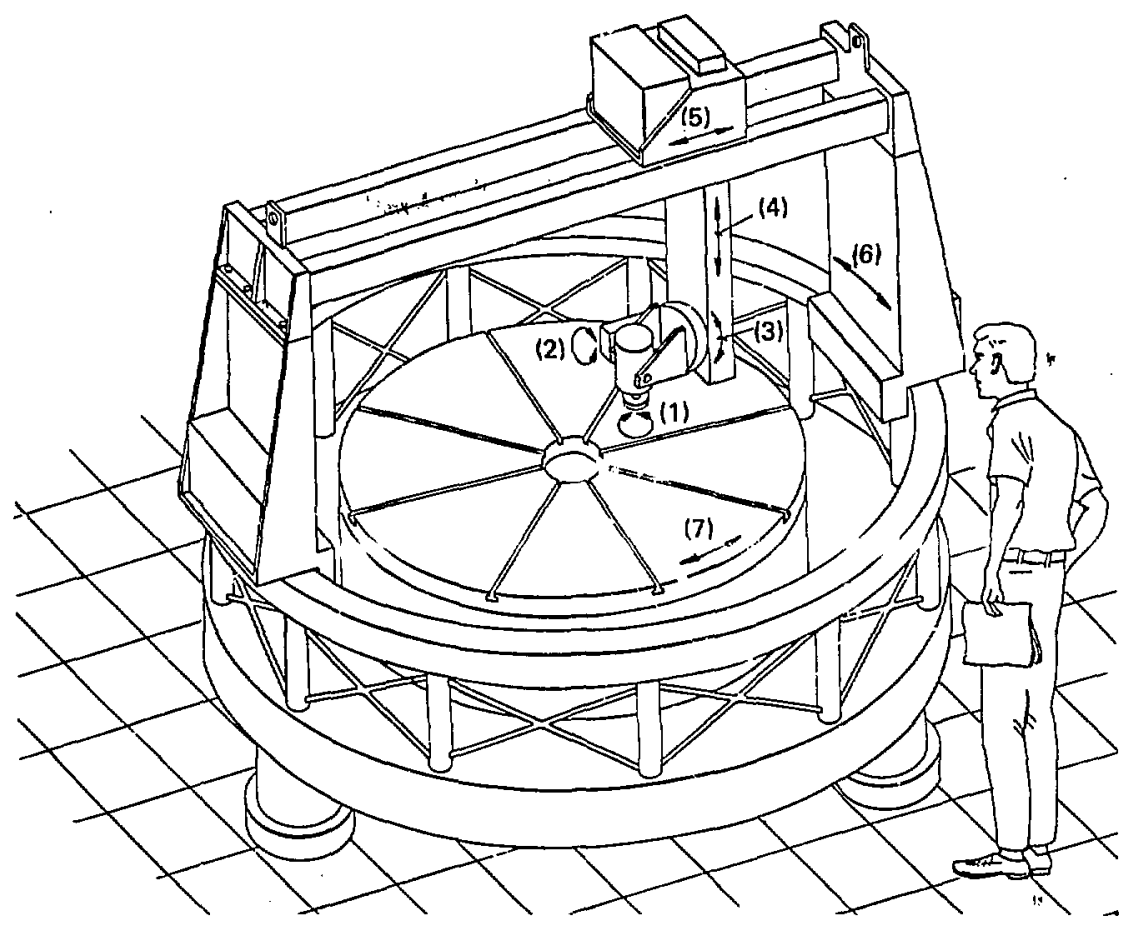

FIC. 14. Polar polishing machine haring seven degrees of freedom.

\subsection{OTHER CONCEPTS FOR REMOVAL, OF MATERIAI.}

Traditionally, the word "polishing" infers removing material through the use of an abrasive media. However, there are other methods for removing inaterial that have been employed for optics finishing, usually with limited success. Scme of these include:

I. Momentum systems using an abrasivecarrying fluid directed tangential to the surface.

2. Chemical removal, preferentially activated by agitation (i.e., a weak chentical erosion system activated by soft brushes or ultra sound).
3. Chemical removal employing successive masking, such as photoetching.

4. Controlled vaporization using laser or electron beams.

Removal methods such as these four may be developed as back-ups to the more conventionai polishing schemes of Sers. 3.3 and 3.4, or they may have application for surface smoothing in particular areas such as at the tip of the inner cone of an axicun. We believe, however, that extension of the present technology developed at LLNL and University of Arizona ${ }^{27}$ for polishing SPDT metab surfaces represents the lowest-risk path for accomplishing the optics goals of the Alpha Laser program. 


\section{CHAPTER 4. DISCUSSION OF MOUNTING, SUBSTRATES, AND COATINGS}

\subsection{MOUNTING OF OPTICAL COMPONENTS}

Methods for accurately fixturing or chucking a wide range of sizes and shapes of parts for SPDT have been developed at LLNL and Y-12 over the past ten or more years. These parts range from small (less than 0.010-in. diameter) spheres to medium size (16-in. diameter) spherical and parabolic mirrors. Past practice has involved specific design of a fixturing method for each part after the detail design of the part has been completed.

Proper mounting or fixturing of HELO for manufacturing, testing, and use in laser systems are similar if not almost identical tasks. Basically, the part must be supported in such a way that the required (i.e., microinch) accuracy of the reflective surface can be generated and maintained throughout all operations and use.

A mounting or fixturing design must take into account the following important factors:

1. Substrate size.

2. Substrate weight.

3. Substrate shape.

4. Substrate elastic properties.

5. Allowable attachment points.

6. Machine environment (centrifugal force, temperature, etc.).

7. Machine operation (cutting, polishing, metrology, etc.).

8. Accuracy requirements.

9. Interface requirements.

If reasonable estimates or specific information is available on the above factors, the design can be carried out in two phases in a manner similar to the approach often used on astronomical telescopes.

First a study is made concentrating on the question of how to mount parts of certain general shapes (e.g., ring, cone, flat, lipped plate). In so doing, various support structures are classified and their sensitivities to elastic properties of the materials are determined. This phase of the study will generate information bearing on both material selection and detailed design practices for actual components. The principal methods used are anaiytical, vith emphasis on finite element model- ing. There would also be enough experimental work done to verify the accuracy of the modeling process.

A second phase begins by selecting a known general method of mounting from phase one, along with an optical component design with minimal sensitivity to the fixture. The second phase then involves detailed modeling of the component's design, experimental testing of the model to refine the accuracy of the design, and the construction and testing of the full-scale mounts or fixtures.

This approach to mounting of optical components was used for the conceptual survey and subsequent selection and detail design of primary mirror mounts for the muliple mirror telescope at the University of Arizona. In that case, careful consideration of the alternatives resulted in an efficient mount design, which subsequently performed as predicted by the analytical models.

As a specific example of the second phase, for optical components with substantial intrinsic stiffness but not enough for three-point support alone, one could investigate the use of three supports that are axially but not radially stiff, with one or more air bags located between the supports. The air bags would be inflated to a pressure that removes close to $100 \%$ of the loads on the three hard mounts. Radial location could be assured by using a slightly interfering cylindrical-toroidal joint at the center of the part.

\subsection{SUBSTRATES}

Most HELO substrates now in use are constructed by brazing together plates of refractory metals (i.e., molybdenum or tungsten). The plates have open passages machined on one side prior to brazing. Closed cooling passages are later formed by the brazed joints. The mirror face plate (typically 0.010 to 0.020 in. thick) is machined and then finished by employing conventional loose abrasive grinding and polishing techniques.

In many applications, severe operational problems have been experienced as a result of corrosion in the internal cooling passages. There have also been problems with face cracking, warping, and long term creep-type distortion. ${ }^{1}$ 
It is expected that during the next few years substrates will be the focus for considerably : $1-$ creased efforts in the development of new materiuls (i.e., carbon-carbon composites), forms, and manufacturing methods of joining, shaping, plating and finishing. ${ }^{2}$

No definitive information on Alpha Laser substrate design and construction was found during the course of this preliminary study.

\subsection{COATINGS}

Thin film coatings for high energy lasers operating in the near infrared wavelength region (2 to $5 \mu \mathrm{m}$ ) have been the subject of many studies in recent years. ${ }^{3,28-33}$ The most comprehensive study was coinpleted recently (March 1980) by H. E. Bennett at Naval Weapons Center, China Lake, CA. ${ }^{3}$ Coating development studies specifically for the Alpha Laser program are underway at Northrup Aviation Corporation, Perkin-Elmer Corporation, Danbury, CT, ${ }^{34}$ and Naval Weapons Center.

H. E. Bennett's study ${ }^{3}$ includes the results of three other independent studies conducted by Optical Coating Labs, Santa Rosa, CA, Eastman Kodak Corporation, Rochester, NY, and PerkinElmer Corporation, Danbury, CT. ${ }^{33}$ All four of the above studies addressed the problems of coating design, deposition, and evaluation related primarily to large-beam transport mirrors $(0.5$ to $4 \mathrm{~m}$ in diameter), but much of the information is also applicable to resonator mirrors such as those used in the Alpha Laser program.

H. E. Bennett ${ }^{3}$ concluded that:

1. Large mirrors have to be coated with an optical thickness uniformity of $1 \%$ or better over the full aperture.

2. The finished, coated mirrors must be evaluated for wavefront distortion at the operating wavelength (i.e., $2.8 \mathrm{\mu m}$ for the Alpha Laser), because the coatings may introduce significant phase distortions.

3. Absolute reflectance of the coated mirror must be 0.998 or better.

He also pointed out that there are important trade-off decisions to be made in budgeting for allowable form (contour) errors to include errors derived from:

1. System/operating effects (e.g., thermal, mounting, dynamic distortions).

2. Finishing operations.

3. Coating operations.

Trade-off decisions must be made realistically, and early in the development of an integrated plan for fabricating the mirrors, in order to avoid costly "overkills" (or "underkills"?) in terms of equipment, facilities, and personnel required to accomplish each step in the fabrication process. 


\section{REFERENCES}

1. J. G. Gowan, Air Force Weapons Laboratory, Albuquerque, NM, private communication (March 1980).

2. K. C. Jungling, Air Force Weapons Laboratory, Albuquerque, NM, private communication (March 1980).

3. H. E. Bennett, Large Optics Study, Naval Weapons Center, China Lake, CA (Draft copy, 1980).

4. Observation based on High Energy Laser Review Group (HELRG) meeting held at Air Force Weapons Laboratory, Kirtland Field, Albuquerque, NM, March 19-20, 1980.

5. R. R. Donaldson, Large Optics Diamond Turning Machine, Vol. I, Lawrence Livermore National Laboratory, Livermore, CA, UCRL-52812 (1979).

6. J. C. Stover, "Roughness Characterization of Smooth Machined Surfaces by Light Scattering," Appl. Optics 14, 1796 (1975).

7. T. T. Saito and J. Arnold, "Metrology of a Diamond Turned Toric Resonator Component," in Proc. Soc. of Photo-Optical Instrumentation Engineers, San Diego, August 26-27, 1976 (Society of PhotoOptical Instrumentation Engineers, Bellingham, WA, 1976), vol. 93.

8. A. M. Ledger, "Inhomogeneous Interface Laser Mirror Coatings," Appl. Optics 18, 2979 (1979).

9. D. L. Decker, "Surface and Optical Studies of Diamond Turned and Other Metal Mirrors," in Proc. Soc. of Photo-Optical Instrumentation Engineers, San Diego, August 26-27, 1976 (Society of PhotoOptical Instrumentation Engineers, Bellingham, WA, 1976), vol. 93, page 71.

10. S. G. Reynolds, "Di'fraction Effects of Diamond Turned Surfaces," in Proceedings of High Power Laser Optical Componenis Meeting, China Lake, 1978 (Naval Weapons Center, China Lake, 1979).

11. J. B. Bryan and O. Mohl, "Microinterferometric Scanning for Full Surface Metrology," Paper 64WA/Prod-15, presented at the American Society of Mechanical Engineers Winter Annual Meeting, New York, Nov. 29-Dec 4, 1964.

12. J. Russon et al., "AXAF Fabrication Technology," presented at Marshall Space Flight Center, Hunstsville, AL, February 8, 1980; unpublished handout material.

13. G. M. Sanger, Lawrence Livermore National Laboratory, Livermore, CA, private communication (March 1980).

14. R. P. Grosso and R. Crane, Jr., "Precise Optical Evaluation Using Phase Measuring Interferometric Techniques," in Proc. Soc. of Photo-Optical Instrumentation Engineers, San Diego. August 24-30, 1979 (Society of Photo-Optical Instrumentation Engineers, Bellingham, WA, 1979), vol. 192, pp. 65-74.

15. R. E. Parks, University of Arizona, Tucson, AZ, private communication (March 1980).

16. H. E. Bennett, Naval Weapons Station, China Lake, CA, private communication (March 1980).

17. K. Narayanasamy, V. Radhakrishnan, and R. G. Narayanamurthi, "An Analysis of the Surface Reproduction Characteristics of Different Replica Materials," presented at the International Conference on Metrology and Properties of Engineering Surfaces, Leicester Polytechnic University, England, April 18-20, 1979; unpublished.

18. E. L. Church, "The Measurement of Surface Texture and Topography by Differential Light Scat tering," presented at the International Conference on Metrology and Properties of Engineering Surfaces, Leicester Polytechrnic University, England, April 18-20, 1979; unpublished.

19. G. E. Sommargren, Optical Heterodyne Profilometry, Lawrence Livermore National Laboratory, Livermore, CA, UCRL-84114 (1980).

20. J. M. Bennett and J. M. Elson, Statistics of Optical Surfaces, Naval Weapons Center, China Lake, CA, Semi-annual Reports 7 and 8, ARPA 2175 (1976).

21. J. M. Bennett, Naval Weapons Center, China Lake, CA, private communication (March 1980).

22. R. R. Donaldson, Lawrence Livermore National Laboratory, Livermore, CA, private communication (May 1980).

23. K. G. Kumanin, Ed., Generation of Optical Surfaces (Focal Press, New York, 1962), p. 147.

24. R. A. Chodzko, S. B. Mason, E. B. Turner, and W. W. Plummer, Jr., "Annular (HSURIA) Resonators: Some Experimental Studies Including Polarization Effects," Appl. Optics 19, 778 (1980). 
25. P. C. Baker, N. J. Brown, T. T. Saito, and W. L. Randall, Diamond Polishing a Diamond Turned X-Ray Microscope, Lawrence Livermore National Laboratory, Livermore, CA, UCRL-77850 (1976).

26. P. C. Baker, J. B. Sonderman, and T. T. Saito, "Finishing of Precision Generated Metal Optical Components," in Proc. Soc. of Photo-Optical Instrumentation Engineers, San Diego, August 19-20. 1975 (Society of Photo-Optical Instrumentation Engineers, Bellingham, WA, 1975), vol. 65, p. 42.

27. R. E. Parks, "Polishing Single Foint Diamond Turned Mirrors," in Proc. Workshop on Optical Fabrication and Testing, San Mateo, 1977 (Optical Society of America, Washington, D.C., 1977).

28. W. P. Latham, Jr., "Analysis of an Imperfectly Coated Conical Element for High Energy Laser Resonators," otherwise unidentifiable material from Air Force Weapons Laboratory (1979).

29. J. Sonderman, Lawrence Livermore National Laboratory, Livermore, CA, private communication (January 1980).

30. E. A. Enemark, "Adherent 3.8 Micrometer Reflector Coatings on Diamond Turned Metal Substrates," in Proceedings of High Power Laser Optical Components Meeting, China Lake, 1978 (Naval Weapons Center, China Lake, 1979).

31. M. Braunstein, "Infrared Coatings for High Energy Luser Reflectors and Windows," in Proc. Soc. of Photo-Optical Instrumentation Engineers, Washington, D.C., March 28-29, 1978 (Society of PhotoOptical Instrumentation Engineers, Bellingham, WA, 1975), vol. 140, p. 85.

32. W. H. Southwell, "Multilayer Coatings Producing 90 Degree Phase Change," Appl. Optics I8, 1875 (1979).

33. R. C. Bastien, W. Hasan, J. R. Kurdock, and A. M. Ledger, Large Optis Coating Chamber Study, Perkins-Elmer Corp., Danbury, CT, Report No. 14634 (1980).

34. R. Lusk, Air Force Weapons Laboratory, Albuquerque, NM, private communication (March 1980). 


\section{APPENDIX A}

Site Visits and Personnel Contacted for the Preliminary Study.

1. LLNL, February 12, 1980 by Richard W. Dyer, W. J. Shafer Associates, Inc. (DARPA consultants).

2. University of Arizona, Optical Sciences Center, March 4, 1980.

R. Parks

E. Straightmatter

3. Air Force Weapons Laboratory, Kirtland Field, Albuquerque, New Mexico, Marcin 5-6, 1980.

a. University of Dayton Research Facility
R. House
D. Mullen
M. Wilkins

b. Developmental Optical Facility

G. Flint

J. Bender

c. Air Force Advanced Resonator/Optics Branch, Advanced Components Section

Lt. Col. K. Jungling

Capt. R. Lusk

Lt. K. Shillito

4. Perkin-Elmer Corp., Electro-Optical Division, Danbury, Connecticut, March 12, 1980.
A. Ledger
P. Mumola
D. H. Mathur

5. Honeywell Electro-Optics Center, Lexington, Mass., March 13, 1980.
F. Johnson
D. Smith
A. Cassie
M. Curcio
J. Zimmerman

6. Air Force Weapons Laboratory, Kirtland Field, Albuquerque, New Mexico, March 19-20, 1980.

a. Air Force Advanced Resonator/Optics Branch, Advanced Components Section Maj. J. Gowan

Lt. K. Shillito

Lt. R. Hoyt

b. Metrology Laboratory

W. Wasson

W. Kuntzler

7. Naval Weapons Center, Michaelson Laboratory, Optical Component Technology Center, March 31, 1980.
H. Bennett
J. Bennett
D. Decker
D. Grandjean
J. Porteus
T. Donovan
G. Winkler 